\title{
Projected changes in climate over the Indus river basin using a high resolution regional climate model (PRECIS)
}

\author{
R. Rajbhandari • A. B. Shrestha · A. Kulkarni • \\ S. K. Patwardhan $\cdot$ S. R. Bajracharya
}

Received: 27 June 2013/Accepted: 15 May 2014/Published online: 3 June 2014

(C) The Author(s) 2014. This article is published with open access at Springerlink.com

\begin{abstract}
A regional climate modelling system, the Providing REgional Climates for Impacts Studies developed by the Hadley Centre for Climate Prediction and Research, has been used to study future climate change scenarios over Indus basin for the impact assessment. In this paper we have examined the three Quantifying Uncertainty in Model Predictions simulations selected from 17-member perturbed physics ensemble generated using Hadley Centre Coupled Module. The climate projections based on IPCC SRES A1B scenario are analysed over three time slices, near future (2011-2040), middle of the twenty first century (2041-2070), and distant future (2071-2098). The baseline simulation (1961-1990) was evaluated with observed data for seasonal and spatial patterns and biases. The model was able to resolve features on finer spatial scales and depict seasonal variations reasonably well, although there were quantitative biases. The model simulations suggest a nonuniform change in precipitation overall, with an increase in precipitation over the upper Indus basin and decrease over the lower Indus basin, and little change in the border area between the upper and lower Indus basins. A decrease in winter precipitation is projected, particularly over the southern part of the basin. Projections indicate greater warming in the upper than the lower Indus, and greater warming in winter than in the other seasons. The
\end{abstract}

\section{R. Rajbhandari}

Tribhuvan University, Kathmandu, Nepal

\author{
A. B. Shrestha $(\bowtie) \cdot$ S. R. Bajracharya \\ International Centre for Integrated Mountain Development \\ (ICIMOD), Kathmandu, Nepal \\ e-mail: Arun.Shrestha@icimod.org
}

\author{
A. Kulkarni · S. K. Patwardhan \\ Indian Institute of Tropical Meteorology, Pune, India
}

simulations suggest an overall increase in the number of rainy days over the basin, but a decrease in the number of rainy days accompanied by an increase in rainfall intensity in the border area between the upper and lower basins, where the rainfall amount is highest.

Keywords Climate change - Future climate scenario Climate projection - Himalaya region · Indus basin

\section{Introduction}

The climate of South Asia is generally dominated by the monsoon. The summer monsoon is the dominant source of moisture over the major part of the region but the percentage of monsoon precipitation in the annual precipitation varies markedly from east to west. In the eastern part of the region the monsoon contributes more than $80 \%$ of the annual precipitation, while in the western part, in northern Pakistan and Afghanistan, the monsoon contributes less than $30 \%$ (Singh et al. 2011). The western part of the region is more influenced by the westerly disturbances, which deliver more than $70 \%$ of the annual precipitation.

As a result of the differences in precipitation climatology, the hydrological regime of the region is also quite different from east to west. Recent studies have shown that the eastern river basins such as the Ganges, and to a certain extent the Brahmaputra, are heavily influenced by the monsoon. In contrast, the western river basins, such as the Indus and Amu Darya, rely heavily on flows derived from the melting of snow and glaciers (Eriksson et al. 2009; Immerzeel et al. 2010). It has been suggested that the impact of climate change on the flow regime will also be different in the different basins. 

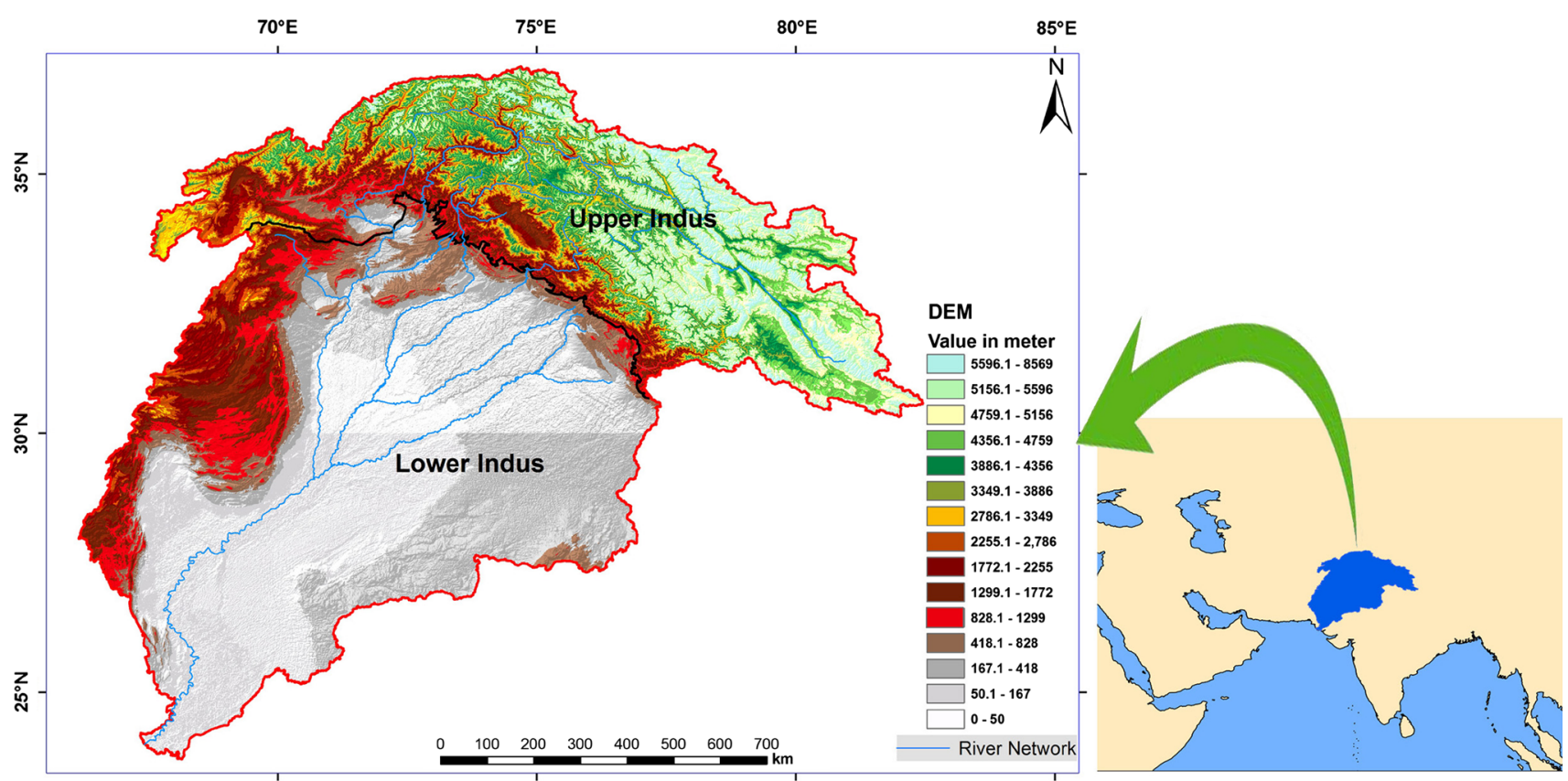

Fig. 1 Location map of the Indus river basin

Climate change scenarios are typically developed over a sub-continental or national domain (Rupa Kumar et al. 2006; Kumar et al. 2011). These scenarios are of little use for impact studies, particularly those related to water resources and resulting socioeconomic impacts. Scenarios developed over basin domains have greater relevance for such studies.

The 1.1 million $\mathrm{km}^{2}$ area of the Indus river basin is shared by four countries: Afghanistan, China, India, and Pakistan, with the largest part in Pakistan (52\%) and India (33\%). The main river originates at Lake Ngangla Rinco on the Tibetan Plateau in the People's Republic of China and is joined by the flow of the tributaries Ravi, Beas, Sutlej, Swat, Chitral, Gilgit, Hunza, Shigar, Shyok, Indus, Shingo, Astor, Jhelum, Chenab, and Kabul, which drain parts of Afghanistan, China, India, and Pakistan (Fig. 1). The upper Indus basin consists of mountainous terrain, and includes parts of the Hindu Kush, Karakorum, and Himalayan mountain ranges; the lower Indus basin comprises the southern plains. The separation is mainly based on altitude. The Indus basin ranks among the most important river basins in the world in terms of human dependence. The river supports a population of about 215 million people, whose livelihoods directly or indirectly depend on it. The basin has a very high population density with an approximate water availability of $1,329 \mathrm{~m}^{3}$ per head (UNEP 2008). The Indus river is the primary source of water for the downstream part of the basin, which contains one of the world's largest irrigation systems. Climate change could have a marked adverse effect on the water resource dependent socioeconomy of the basin, as noted by various authors (Rees and Collins 2006; Immerzeel et al. 2009, 2010; Briscoe 2010). Climate scenarios using simulations from high resolution models provide a useful opportunity to assess the impact of future climate change.

This study attempts to examine the projected future change in the climate over the Indus basin using outputs from the Providing REgional Climates for Impact Studies (PRECIS) model driven by data for three different lateral boundary conditions (LBC) from Quantifying Uncertainty in Model Predictions (QUMP) simulations using SRES A1B scenario.

\section{Data and analysis}

\subsection{The PRECIS model}

To develop the high resolution climate change scenarios for impact assessment studies, a high resolution regional climate model, PRECIS, developed by the Hadley Centre, UK is run at IITM, Pune, at $50 \mathrm{~km} \times 50 \mathrm{~km}$ horizontal resolution over the South Asian domain. The basic aspects explicitly handled by the model are briefly outlined in Noguer et al. (2002). The perturbed physics approach was developed in response to the call for better quantification of uncertainties in climate projections (IPCC 2007). The basic approach involves taking a single model structure and making perturbations to the values of parameters in the model, based on the discussions with scientists involved in 
Table 1 Seasonal and annual rainfall (mm) with standard deviation for baseline (1961-1990) and A1B future scenarios

\begin{tabular}{|c|c|c|c|c|c|c|c|c|c|c|c|c|}
\hline \multicolumn{7}{|l|}{ Rainfall mean } & \multicolumn{6}{|c|}{ Standard deviation } \\
\hline & DJF & MAM & JJAS & ON & Annual & Rainy day & DJF & MAM & JJAS & ON & Annual & Rainy day \\
\hline \multicolumn{13}{|l|}{ Q0 } \\
\hline Observed & 58 & 81 & 191 & 16 & 346 & 106 & 17.3 & 26.3 & 47.3 & 7.3 & 47.7 & 12 \\
\hline Baseline & 90 & 143 & 333 & 61 & 627 & 159 & 44.8 & 51.7 & 75.2 & 36.6 & 93.7 & 18 \\
\hline 2011-2040 & 86 & 144 & 372 & 64 & 666 & 159 & 59.8 & 71.2 & 87.1 & 47.8 & 118.2 & 23 \\
\hline 2041-2070 & 112 & 149 & 398 & 74 & 733 & 165 & 64.0 & 52.8 & 111.5 & 42.0 & 130.7 & 17 \\
\hline 2071-2098 & 104 & 161 & 411 & 64 & 740 & 162 & 54.3 & 71.3 & 104.6 & 40.9 & 107.1 & 17 \\
\hline \multicolumn{13}{|l|}{ Q1 } \\
\hline Baseline & 112 & 156 & 236 & 66 & 570 & 154 & 39.5 & 50.3 & 54.8 & 45.2 & 89.1 & 14 \\
\hline 2011-2040 & 106 & 153 & 275 & 66 & 600 & 158 & 44.6 & 54.0 & 81.6 & 29.3 & 105.5 & 19 \\
\hline 2041-2070 & 119 & 159 & 239 & 74 & 586 & 156 & 55.6 & 47.2 & 67.5 & 41.6 & 96.9 & 16 \\
\hline 2071-2098 & 135 & 155 & 256 & 79 & 625 & 158 & 61.1 & 45.0 & 79.3 & 35.6 & 111.3 & 20 \\
\hline \multicolumn{13}{|l|}{ Q14 } \\
\hline Baseline & 146 & 176 & 286 & 89 & 698 & 172 & 66.6 & 57.3 & 53.1 & 52.6 & 91.0 & 16 \\
\hline 2011-2040 & 156 & 202 & 342 & 115 & 816 & 178 & 52.9 & 68.6 & 66.2 & 53.8 & 102.0 & 16 \\
\hline 2041-2070 & 152 & 178 & 327 & 95 & 752 & 172 & 64.5 & 56.4 & 64.3 & 43.9 & 92.0 & 14 \\
\hline 2071-2098 & 180 & 186 & 331 & 107 & 804 & 177 & 72.6 & 56.8 & 72.1 & 45.3 & 114.8 & 13 \\
\hline
\end{tabular}

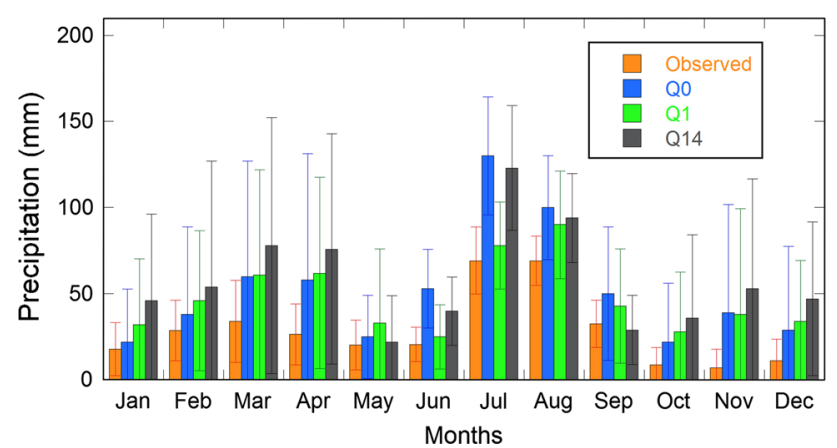

Fig. 2 Annual cycles of mean precipitation over the Indus basin for the three QUMP simulations Q0, Q1, and Q14 compared with APHRODITE precipitation data during the baseline period (1961-1990). Error bars depict one standard deviation of monthly mean values over the baseline period

the development of different parameterization schemes. In some cases, different variants of physical schemes may also be switched in and out. Any number of experiments that are routinely performed with single model can then be produced in an "ensemble mode" subject to constraints on computer time. A significant amount of perturbed physics experimentation has been done with Hadley Centre Coupled Module (HadCM3) and variants, starting with the work of Murphy et al. (2004) and Stainforth et al. (2005). The parent model HadCM3 shows reasonable skill in reproducing the observed features of South Asian climate (Kripalani et al. 2007; Sabade et al. 2011). The QUMP simulations, comprise of 17 versions of the fully coupled version of HadCM3, one with the standard parameter setting and 16 versions in which 29 of the atmosphere component parameters are simultaneously perturbed (Collins et al. 2006). The intercomparison of 17 members of QUMP reveals the strengths and weaknesses of these members in simulating the gross features of global climate in general and the tropical rain belts in particular. The spatial pattern of Indian summer monsoon rainfall i.e. rainfall maxima over west coast and head Bay of Bengal and comparatively dry regions over north west and south east peninsular India are well captured by global runs of Q0, Q1 and Q14. These members also capture the annual cycles of rainfall and surface air temperatures reasonably well. (Kamala 2008). Based on a preliminary evaluation of these 17 global runs for their ability to simulate the gross features of Indian monsoon, the LBCs of three QUMP simulations viz. Q0, Q1 and Q14 were made available by Hadley Centre, UK to IITM.

Domain size and horizontal resolution are key factors for regional climate simulation (Bhaskaran et al. 1996; Vannitsem and Chome 2005; Bhaskaran et al. 2012). The domain size needs to be sufficiently large to capture regional physical processes (Giorgi and Mearns 1999) to capture the correct climate response but not too large that the climate of the RCM deviates significantly from the GCM (Jones et al. 2004). PRECIS has been configured for a domain extending from about $1.5^{\circ} \mathrm{N}-38^{\circ} \mathrm{N}$ and $56^{\circ} \mathrm{E}-$ $103^{\circ} \mathrm{E}$. It has been demonstrated that with this domain, the RCM provides a realistic representation of the intraseasonal variability of the Indian summer monsoon, 

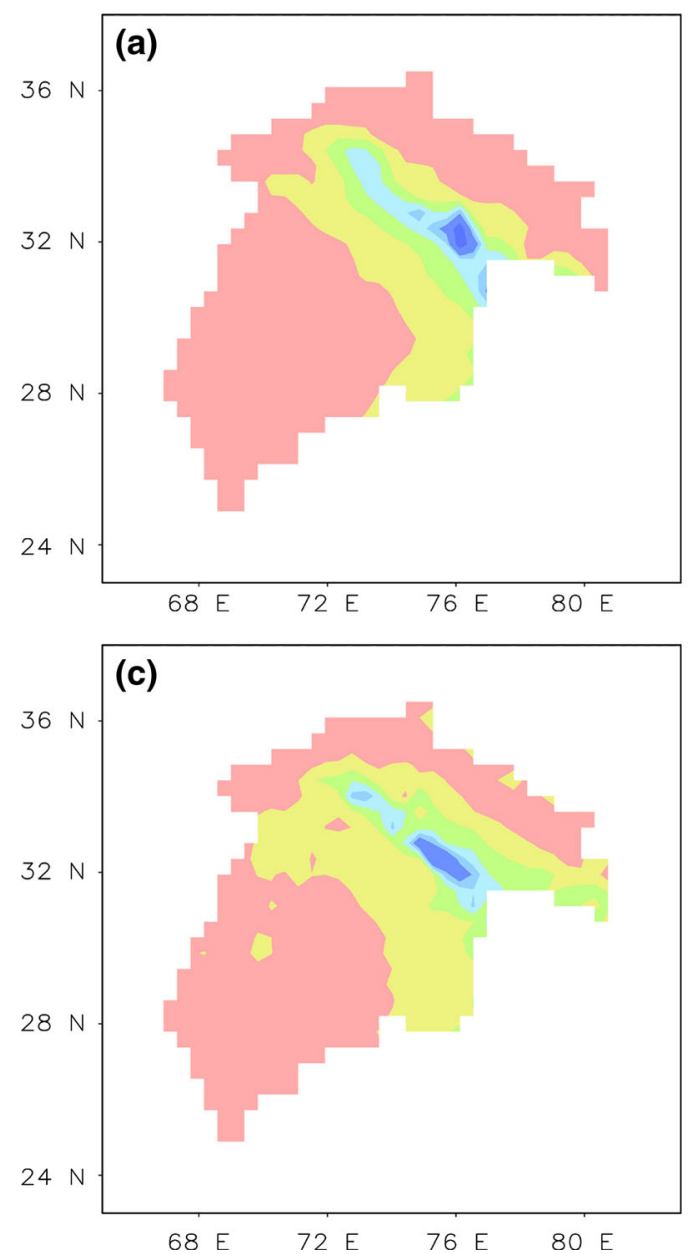

(b)

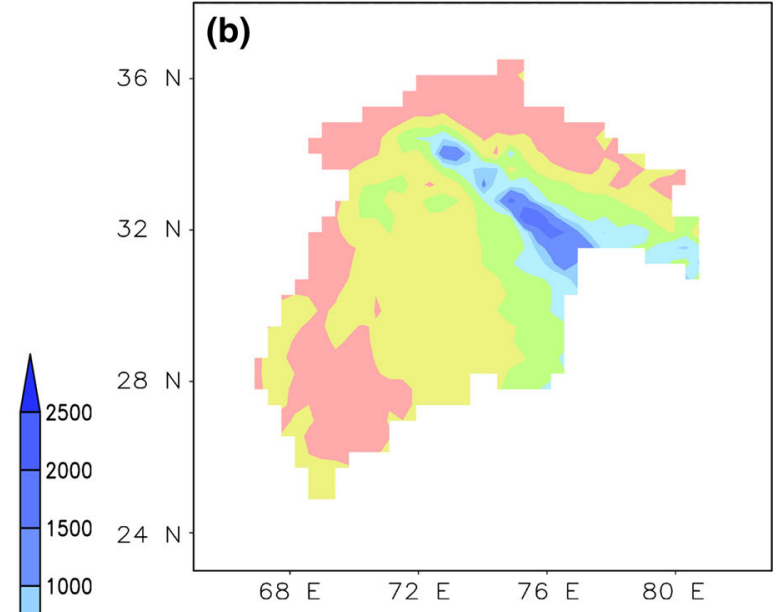

(d)

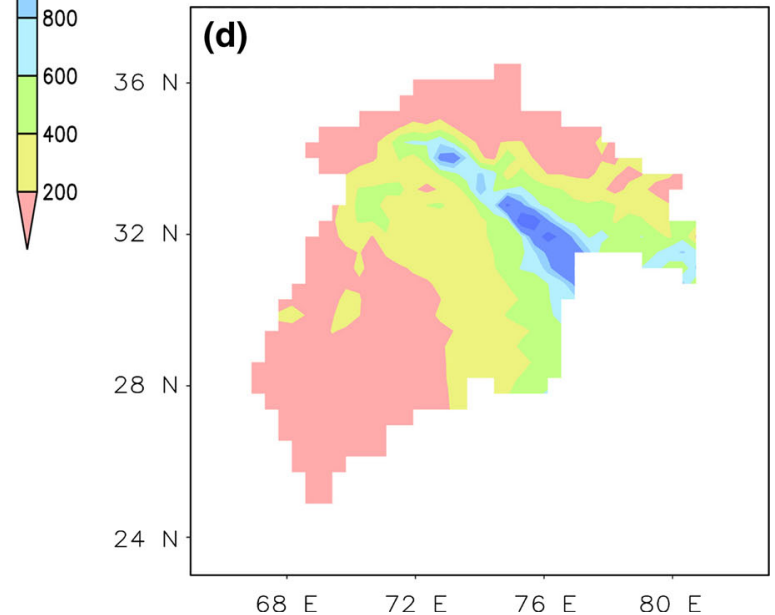

Fig. 3 Spatial distribution of the summer monsoon (June-September) rainfall (mm) baseline period (1961-1990) as captured by a APHRODITE compared with three PRECIS simulation b Q0, c Q1, and d Q14

responding to both the global forcing via the LBC and internal dynamics (Bhaskaran et al. 1998).

Here, three simulations from a seventeen-member perturbed physics ensemble (PPE) produced using HadCM3 under the QUMP project of Hadley Centre Met Office, U.K., have been used as LBC for the 138 year simulations of the regional climate model-PRECIS. These three simulations have been validated for their skill in simulating the present climate over India (Patwardhan 2013). This study has shown that all the three regional QUMP simulations capture the seasonal climatology and annual cycle of rainfall as well as surface air temperature reasonably well over Indian landmass. However, Q1 shows dry bias over west coast as far as the summer monsoon rainfall is concerned. The number of rainy days and the intensity of rainy days are well simulated in the QUMP runs. The intensity of rainfall on a rainy day is more along the Western Ghats and over northeast India and matches well with the observed intensity pattern. The continuous 138-year simulations of the regional climate model provide an opportunity to assess the impact of climate change over the Indus basin for three time slices representing the near (2011-2040, or 2020s), medium (2041-2070, or 2050s), and distant (2071-2098, or 2080s) future for long implications for policy at these timescales. The selection of the domain size and the three QUMPs are also discussed by Rupa Kumar et al. (2006) and Kumar et al. (2011) respectively. The analysis was based on the outputs of the three simulations-Q0, Q1, and Q14-for rainfall, maximum temperature, and minimum temperature over the Indus basin. Extreme rainfall and temperature, with the number of rainy days and rainfall intensity, was also analysed. The following sections provide a further breakdown of the basin into sub-basins based mainly on altitude, viz., upper Indus and lower Indus, and analyses of the projected simulations. 

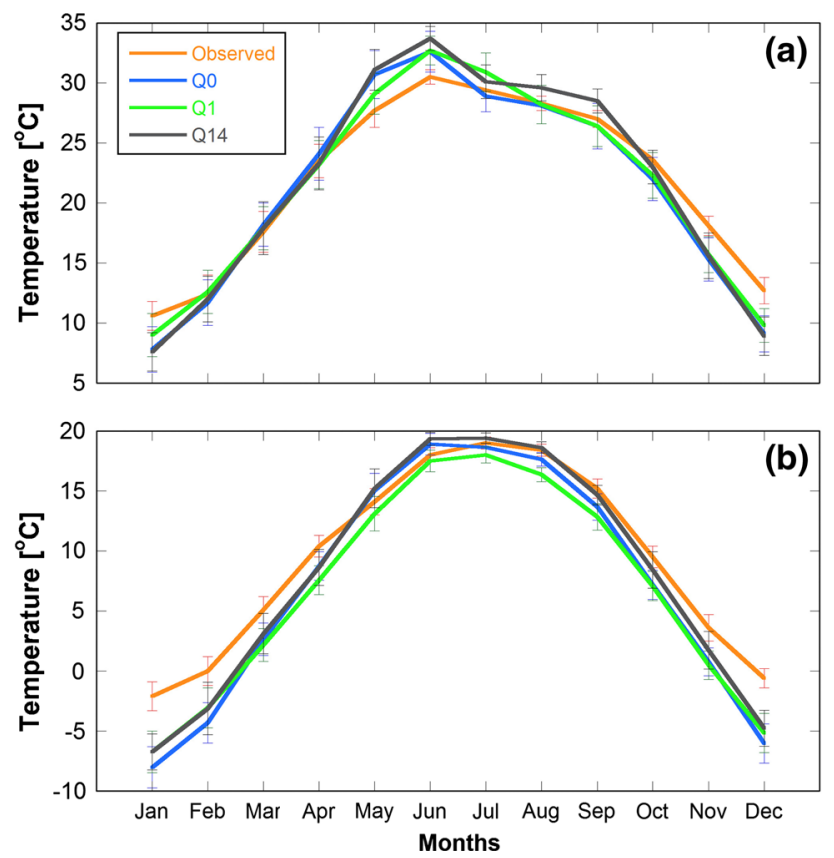

Fig. 4 Annual cycles of monthly mean temperature over the Indus basin for three QUMP simulations Q0, Q1, and Q14 compared with observed CRU for the baseline period (1961-1990), a maximum temperature and b minimum temperature. Error bars depict one standard deviation of monthly mean values over the baseline period

\subsection{Observation data}

For the evaluation of climate model outputs it is important to understand key issues and limitations associated with observational datasets used. Station based precipitation is likely to be underestimated in the high mountainous area as majority of the stations are located in the low elevation. Further, gauge under-catch bias is another source of underestimation. The underestimation could be as much as $30 \%$ or even higher (Adam and Lettenmaier 2003). Since the meteorological stations are located at valleys, observed temperature will have warm bias over the Himalayan region. APHRODITE's Water Resources (Asian Precipitation-Highly—Resolved Observational Daily Integration Towards Evaluation of Water Resources, www.chikyu.ac. $\mathrm{jp} / \mathrm{precip} /$ ) data were taken as the base data for evaluation of the seasonal rainfall simulation by PRECIS (Yatagai et al. 2012). These high-resolution daily gridded precipitation datasets are presently the only long-term product available in continental-scale. These gridded datasets are based on rain-gauge observations collected from $5,000-12,000$ stations and have substantially improved the depiction of the areal distribution and variability of the rainfall over Himalayas. Although the key strength of the product is the high density of network it lacks observation data from India. For the qualitative and quantitative comparison we have used APHRO_V1101 datasets at a resolution of $0.25^{\circ}$ and $0.25^{\circ}$ latitude and longitude available for the period 1951-2007 for the monsoon Asia domain $\left(60^{\circ}-150^{\circ} \mathrm{E}, 15^{\circ}-55^{\circ} \mathrm{N}\right)$. For the present analysis, the baseline period was taken from 1961 to 1990 . A global gridded data set from the Climatic Research Unit (CRU), University of East Anglia was used to evaluate the seasonal temperature simulation (New et al. 2002). CRU datasets contains only 73 stations for whole South Asia region and even less in the Himalayan region. There are 25 observation stations covering the Indus basin. High resolution
Table 2 Seasonal and annual maximum temperature $\left({ }^{\circ} \mathrm{C}\right)$ with standard deviation for baseline (1961-1990) and A1B future scenarios

\begin{tabular}{|c|c|c|c|c|c|c|c|c|c|c|}
\hline & \multicolumn{5}{|c|}{ Temperature mean maximum } & \multicolumn{5}{|c|}{ Standard deviation } \\
\hline & DJF & MAM & JJAS & $\mathrm{ON}$ & Annual & DJF & MAM & JJAS & ON & Annual \\
\hline \multicolumn{11}{|l|}{ Q0 } \\
\hline Observed & 11.9 & 22.9 & 28.8 & 20.8 & 21.1 & 0.9 & 1 & 0.4 & 0.6 & 0.4 \\
\hline Baseline & 9.5 & 24.3 & 29.0 & 18.6 & 20.4 & 1.4 & 1.6 & 1.0 & 1.6 & 1.4 \\
\hline $2011-2040$ & 11.4 & 25.4 & 30.1 & 20.0 & 21.7 & 1.6 & 2.8 & 1.5 & 2.4 & 2.1 \\
\hline $2041-2070$ & 12.7 & 27.0 & 31.6 & 21.2 & 23.1 & 1.4 & 2.2 & 1.2 & 1.7 & 1.6 \\
\hline $2071-2098$ & 14.2 & 28.1 & 32.8 & 22.5 & 24.4 & 1.5 & 1.8 & 1.0 & 1.2 & 1.4 \\
\hline \multicolumn{11}{|l|}{ Q1 } \\
\hline Baseline & 10.5 & 23.4 & 29.6 & 19.0 & 20.6 & 1.2 & 1.3 & 0.8 & 1.4 & 1.2 \\
\hline $2011-2040$ & 12.1 & 25.3 & 30.1 & 19.6 & 21.8 & 1.0 & 1.6 & 1.4 & 1.9 & 1.5 \\
\hline $2041-2070$ & 13.4 & 26.1 & 31.9 & 21.3 & 23.2 & 1.0 & 1.3 & 1.0 & 1.3 & 1.2 \\
\hline 2071-2098 & 13.8 & 27.2 & 32.9 & 22.2 & 24.0 & 1.4 & 1.5 & 1.2 & 1.8 & 1.5 \\
\hline \multicolumn{11}{|l|}{ Q14 } \\
\hline Baseline & 9.5 & 24.1 & 30.5 & 19.3 & 20.8 & 1.3 & 1.7 & 0.7 & 1.3 & 1.3 \\
\hline 2011-2040 & 11.1 & 25.5 & 31.3 & 20.3 & 22.0 & 1.3 & 1.5 & 1.0 & 1.1 & 1.2 \\
\hline 2041-2070 & 13.2 & 27.8 & 33.4 & 22.8 & 24.3 & 1.5 & 1.6 & 1.1 & 1.6 & 1.4 \\
\hline 2071-2098 & 13.9 & 28.9 & 35.1 & 23.8 & 25.4 & 1.5 & 1.7 & 1.1 & 1.3 & 1.4 \\
\hline
\end{tabular}


Table 3 Seasonal and annual minimum temperature $\left({ }^{\circ} \mathrm{C}\right)$ with standard deviation for baseline (1961-1990) and A1B future scenarios

\begin{tabular}{|c|c|c|c|c|c|c|c|c|c|c|}
\hline & \multicolumn{5}{|c|}{ Temperature mean maximum } & \multicolumn{5}{|c|}{ Standard deviation } \\
\hline & DJF & MAM & JJAS & ON & Annual & DJF & MAM & JJAS & $\mathrm{ON}$ & Annual \\
\hline \multicolumn{11}{|l|}{ Q0 } \\
\hline Observed & -0.9 & 9.9 & 17.7 & 6.6 & 8.3 & 0.6 & 0.7 & 0.4 & 0.9 & 0.4 \\
\hline Baseline & -6.2 & 8.8 & 17.2 & 4.0 & 6.0 & 1.5 & 1.9 & 1.6 & 2.7 & 1.9 \\
\hline $2011-2040$ & -4.4 & 9.6 & 18.5 & 5.9 & 7.4 & 1.4 & 2.1 & 0.7 & 2.6 & 1.7 \\
\hline $2041-2070$ & -2.6 & 11.4 & 20.0 & 7.5 & 9.1 & 1.2 & 1.7 & 0.5 & 1.8 & 1.3 \\
\hline $2071-2098$ & -1.1 & 12.7 & 21.1 & 8.6 & 10.3 & 1.3 & 1.1 & 0.4 & 1.2 & 1.0 \\
\hline \multicolumn{11}{|l|}{ Q1 } \\
\hline Baseline & -5.0 & 7.6 & 16.2 & 3.8 & 5.7 & 1.2 & 0.7 & 0.4 & 0.9 & 0.8 \\
\hline $2011-2040$ & -3.5 & 9.8 & 17.4 & 5.3 & 7.2 & 1.1 & 1.1 & 0.6 & 1.3 & 1.0 \\
\hline $2041-2070$ & -1.9 & 10.6 & 18.7 & 6.6 & 8.5 & 1.2 & 0.9 & 0.5 & 1.3 & 1.0 \\
\hline 2071-2098 & -1.2 & 11.7 & 19.8 & 7.9 & 9.6 & 1.2 & 1.1 & 0.6 & 1.3 & 1.1 \\
\hline \multicolumn{11}{|l|}{ Q14 } \\
\hline Baseline & -4.9 & 9.0 & 18.0 & 5.1 & 6.8 & 1.1 & 1.2 & 0.3 & 1.1 & 0.9 \\
\hline 2011-2040 & -3.0 & 10.7 & 19.5 & 7.2 & 8.6 & 1.0 & 1.1 & 0.6 & 1.4 & 1.0 \\
\hline $2041-2070$ & -1.1 & 12.9 & 21.3 & 9.5 & 10.6 & 1.3 & 1.1 & 0.6 & 1.7 & 1.2 \\
\hline 2071-2098 & 0.1 & 14.1 & 22.9 & 10.7 & 11.9 & 0.9 & 1.3 & 0.7 & 1.1 & 1.0 \\
\hline
\end{tabular}

gridded monthly datasets at a resolution of $0.50^{\circ}$ and $0.50^{\circ}$ latitude and longitude are available for the period 1901-2000 for the global domain. Due to its availability in daily basis, global $1^{\circ}$ daily maximum and minimum temperatures from Princeton University Hydroclimatology Group Bias Corrected Meteorological Forcing Datasets (Sheffield et al. 2006) were used for the extreme temperature analysis. These datasets are the blend of reanalysis data with globally observation-based datasets. Known biases in the reanalysis precipitation and near surface meteorology have been corrected. Periodically detected spuriously high values mainly due to high daily temperature range (DTR) values in CRU have also been corrected (Terrestrial Hydrology Research Group 2013) but the data is still far from error free. These datasets are the only longterm available datasets in finest resolution.

\section{Results and discussion}

\subsection{Evaluation of PRECIS simulation}

\subsubsection{Precipitation}

The regional simulations generated from the three QUMPs using PRECIS were studied in detail to evaluate the skill of the model in representing the regional climatological features, especially the summer monsoon (June-September) and winter (December-February) rainfall characteristics. Seasonal rainfall statistics for the three simulations for three time slices and a baseline are given in Table 1. All three simulations resulted in a substantial wet bias over the basin. Of the three simulations, Q1 estimated lowest amount for the monsoon season over the whole basin with $236 \mathrm{~mm}$ rainfall and $54.8 \mathrm{~mm}$ standard deviation. This value was closest to the APHRODITE estimated value of $191 \mathrm{~mm}$. Q0 and Q14 estimated rainfall of 333 and $286 \mathrm{~mm}$ with standard deviations of 75.2 and $53.1 \mathrm{~mm}$, respectively. In the winter season, the Q0 simulation of $90 \mathrm{~mm}$ was closest to the APHRODITE estimate of $58 \mathrm{~mm}$. Wet bias over South Asia has been reported by several previous studies (Rupa Kumar et al. 2006; Kumar et al. 2011; Syed et al. 2013). Rupa Kumar et al. (2006) suggested that wet bias may be partly due to the procedures used in determining the spatially averaged observed rainfall quantities. Weakening of the zonal temperature gradient in equatorial Pacific sea surface temperature (SST) in the model leading to increase in monsoon rainfall in response to warming has been attributed to wet bias (Turner and Annamalai 2012). A climate change study over India showed the Q0 and Q14 simulations to have a wet bias and Q1 a dry bias (Kumar et al. 2011), whereas other similar studies over India showed a wet bias (Rupa Kumar et al. 2006; Syed et al. 2013). The PRECIS simulations also overestimated the number of rainy days in a year (a day with area average rainfall $\geq 1.0 \mathrm{~mm}$ ). APHRODITE estimated 106 rainy days annual average for the baseline period 1961-1990, whereas PRECIS estimated 159, 154, and 172 days for the Q0, Q1, and Q14 simulations, respectively.

The model has captured the general seasonal accumulation and monthly progression of the annual cycle 

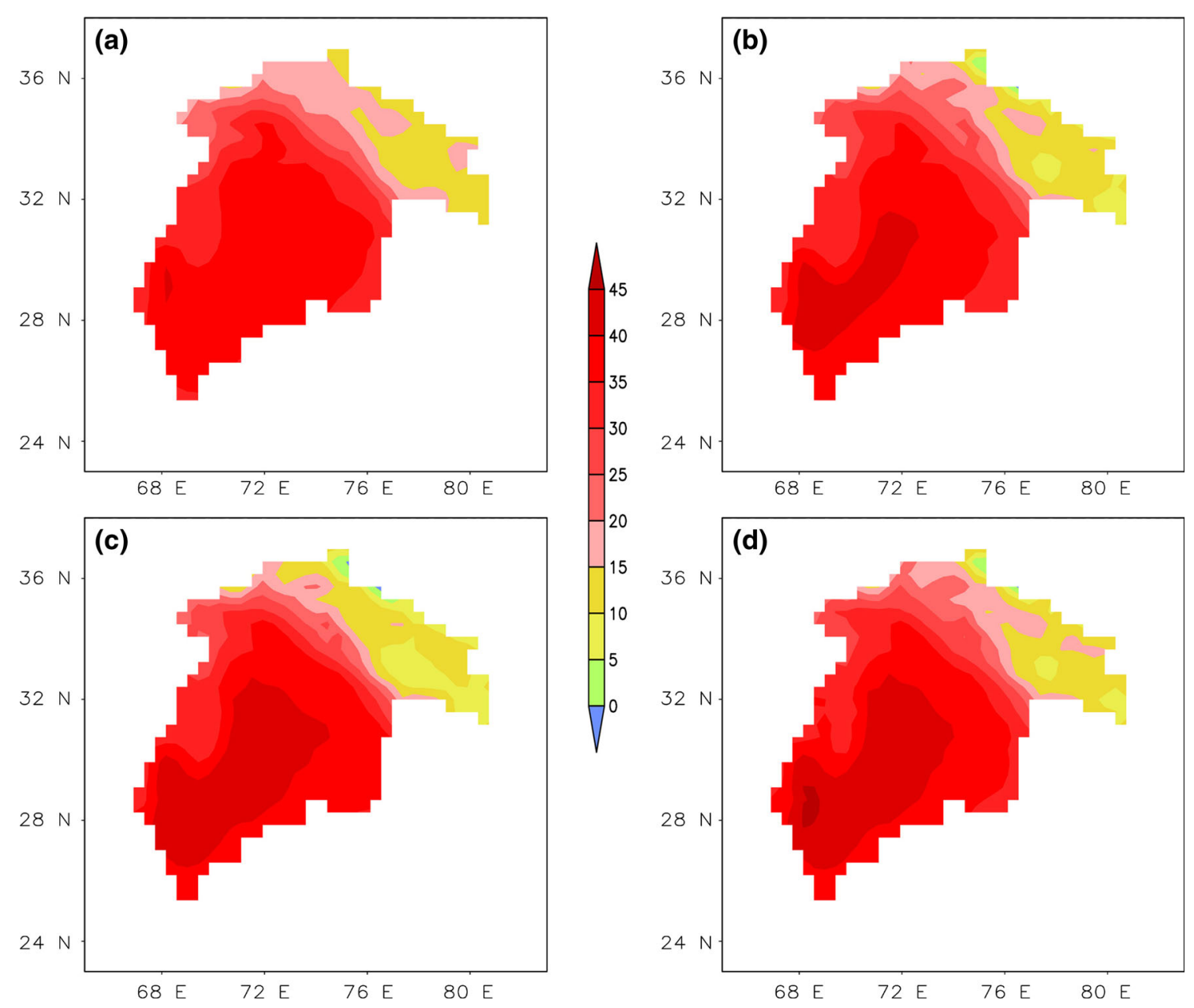

Fig. 5 Spatial pattern of mean maximum temperature $\left({ }^{\circ} \mathrm{C}\right)$ during monsoon season (June-September) for the baseline period $(1961-1990)$ as captured by a CRU and three PRECIS simulations, b Q0, c Q1, and d Q14

reasonably well (Fig. 2). Although the model generally overestimated, the monthly values are within one standard deviation of observed values except for the months of July and August in the Q0 simulation. Q1 simulated values are closer to observed values for the monsoon months, and Q0 values are closer to observed values for the other months.

The spatial distribution of seasonal rainfall estimated by APHRODITE and as simulated by PRECIS for the baseline period (1961-1990) is shown in Fig. 3 for summer monsoon (June-September). Rainfall distribution over the whole basin was simulated reasonably well by the model for both the winter (December-February) and summer seasons. The baseline simulations appear to provide an adequate representation of the distribution pattern except over the eastern section of the northern parts of the basin. There were also quantitative biases in the simulated rainfall.

\subsubsection{Temperature}

Baseline maximum and minimum temperatures were compared with $\mathrm{CRU}$ data to evaluate the model. The maximum temperatures were used to evaluate the skill for the summer monsoon season (June-September) and the minimum temperatures for the winter season (December-February). Annual cycle of the mean monthly maximum and minimum temperature for CRU and three QUMP simulations is provided in Fig. 4. Over the Indus basin, the model simulated maximum temperatures were close to observed during the pre-monsoon season, during May and June the model overestimated and from October to February the model underestimates but all values were within one standard deviation. In case of minimum temperature, except during summer monsoon season the model underestimates. 
Fig. 6 Baseline (1961-1990) and future projections (2011-2040, 2041-2070 and 2071-2098) of monthly precipitation (bars) and temperature (lines) for the three simulations a Q0, b Q1 and $\mathbf{c}$ Q14
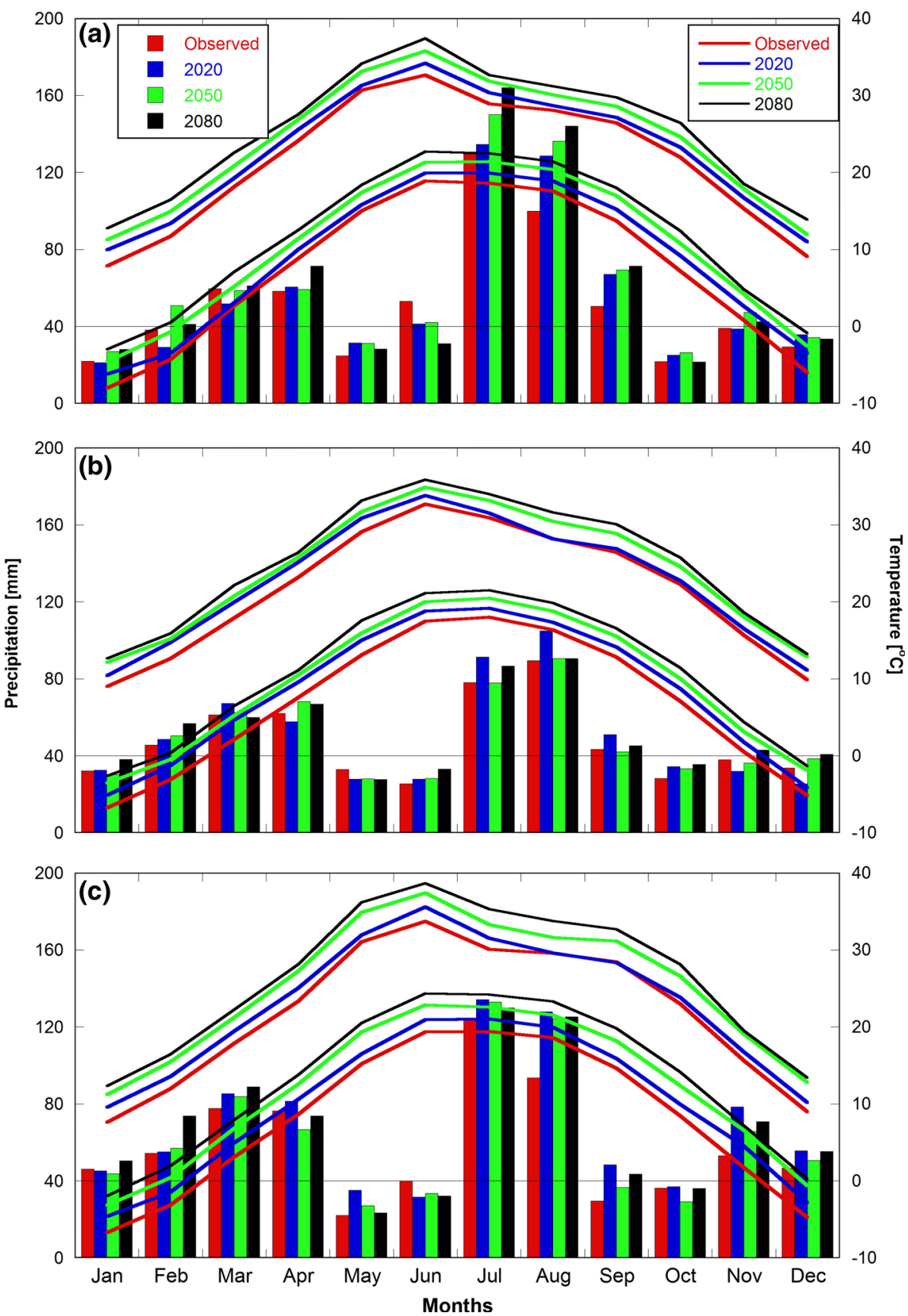

Seasonal statistics for the maximum and minimum temperatures for the three simulations for three time slices and the baseline period are given in Table 2 and Table 3 . During the summer season, the model estimated value for maximum temperature over the whole basin of $29.0^{\circ} \mathrm{C}(\mathrm{Q} 0$ simulation) was very close to the observed value of $28.8^{\circ} \mathrm{C}$. The mean maximum temperature for the summer monsoon season was highest in the Q14 simulation: $30.5^{\circ} \mathrm{C}$ with a standard deviation of $0.7^{\circ} \mathrm{C}$. The values for Q0 and Q1 were 29.0 and $29.6{ }^{\circ} \mathrm{C}$, with standard deviation of $1.0-0.8^{\circ} \mathrm{C}$, respectively. However, during the winter season, the model appears to underestimate the minimum temperature with values of $-6.2,-5.0$, and $-4.9^{\circ} \mathrm{C}$ for Q0, Q1, and Q14 simulations respectively, compared to the CRU estimate of $-0.9^{\circ} \mathrm{C}$.

The spatial temperature distribution estimated from CRU data and as simulated by PRECIS for the baseline period (1961-1990) is shown for mean maximum temperature during the summer monsoon season in Fig. 5. The spatial pattern of mean minimum temperature also 

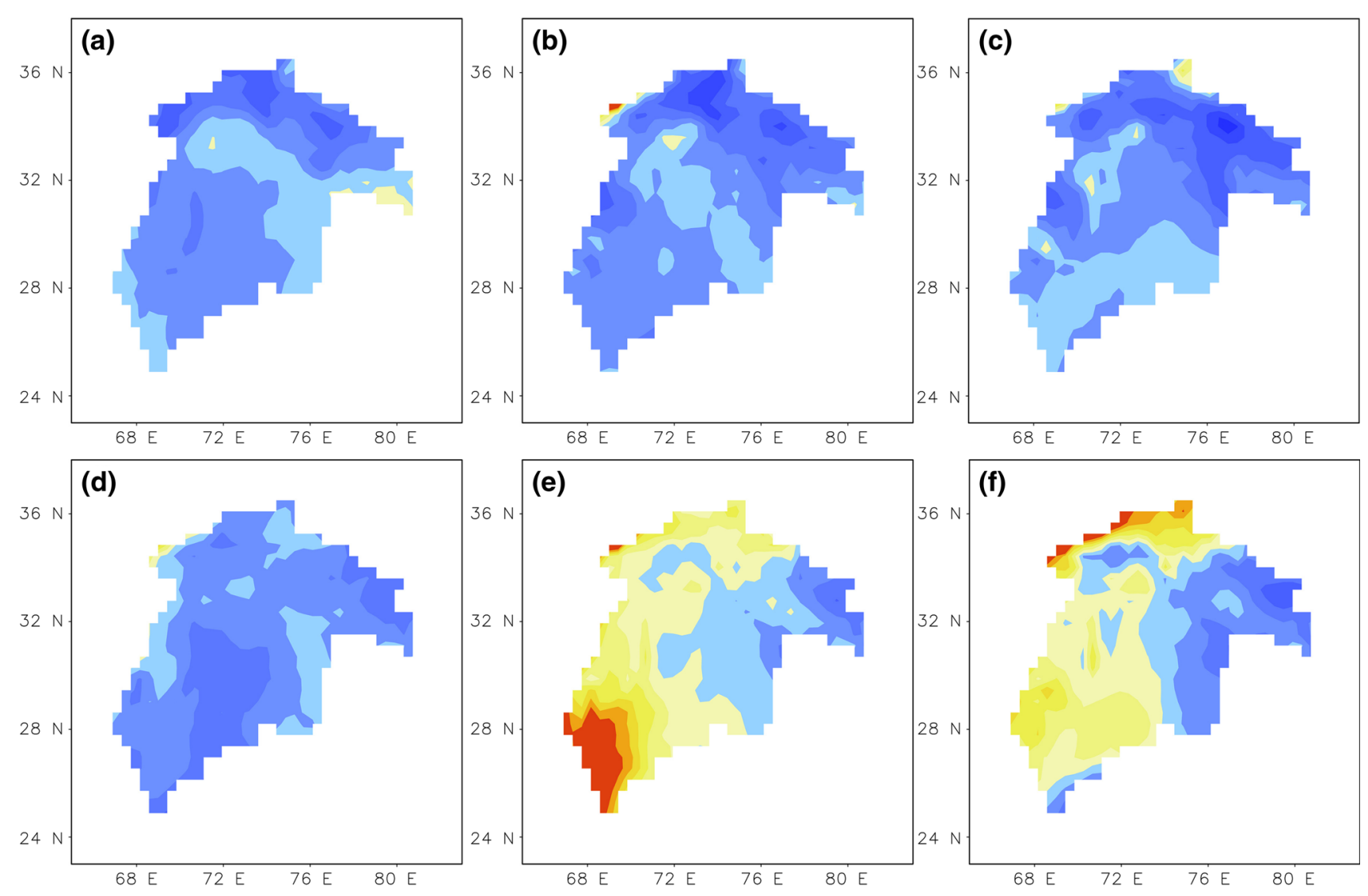

(f)

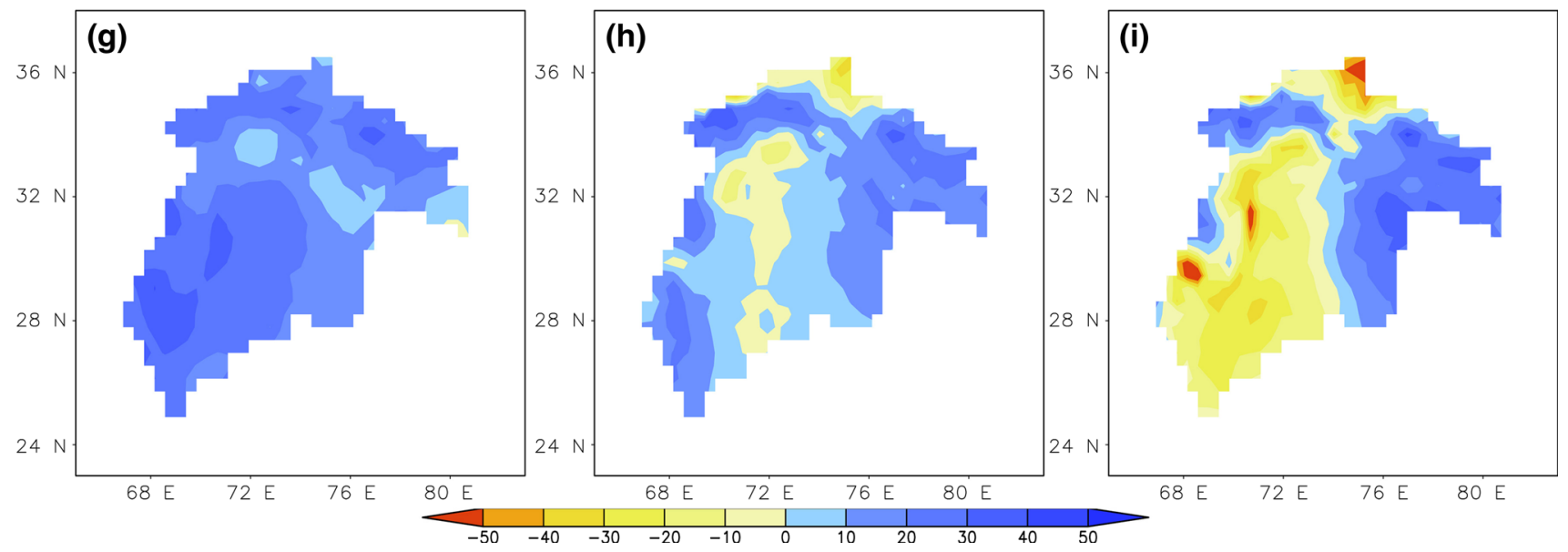

Fig. 7 Projected change in mean summer monsoon rainfall (\%) with respect to baseline 1961-1990 in the 2011-2040 (left column), 2041-2070 (middle column), and 2071-2098 (right column) periods for the three PRECIS simulations Q0 (top row), Q1 (middle row), and Q14 (bottom row)

captured well by the model simulations, but with a distinct cold bias over the upper Indus. Of the three simulations, Q1 has a relatively cold bias, as previously reported by (Rupa Kumar et al. 2006) over India. The cold bias has also been reported by other studies and has been attributed to the prescribed land-use distribution in Biosphere Atmosphere Transfer Scheme (BATS) (Xue et al. 1996; Suh and Lee 2004; Dimri 2012).

\subsection{Projections of future climate}

\subsubsection{Projected changes in annual cycles, precipitation}

The baseline and projected monthly precipitation over Indus is shown in Fig. 6 (bars). The Q0 projections suggest a gradual increase in precipitation from the 2020s (2011-2040), to the 2050s (2041-2070), and 2080s 

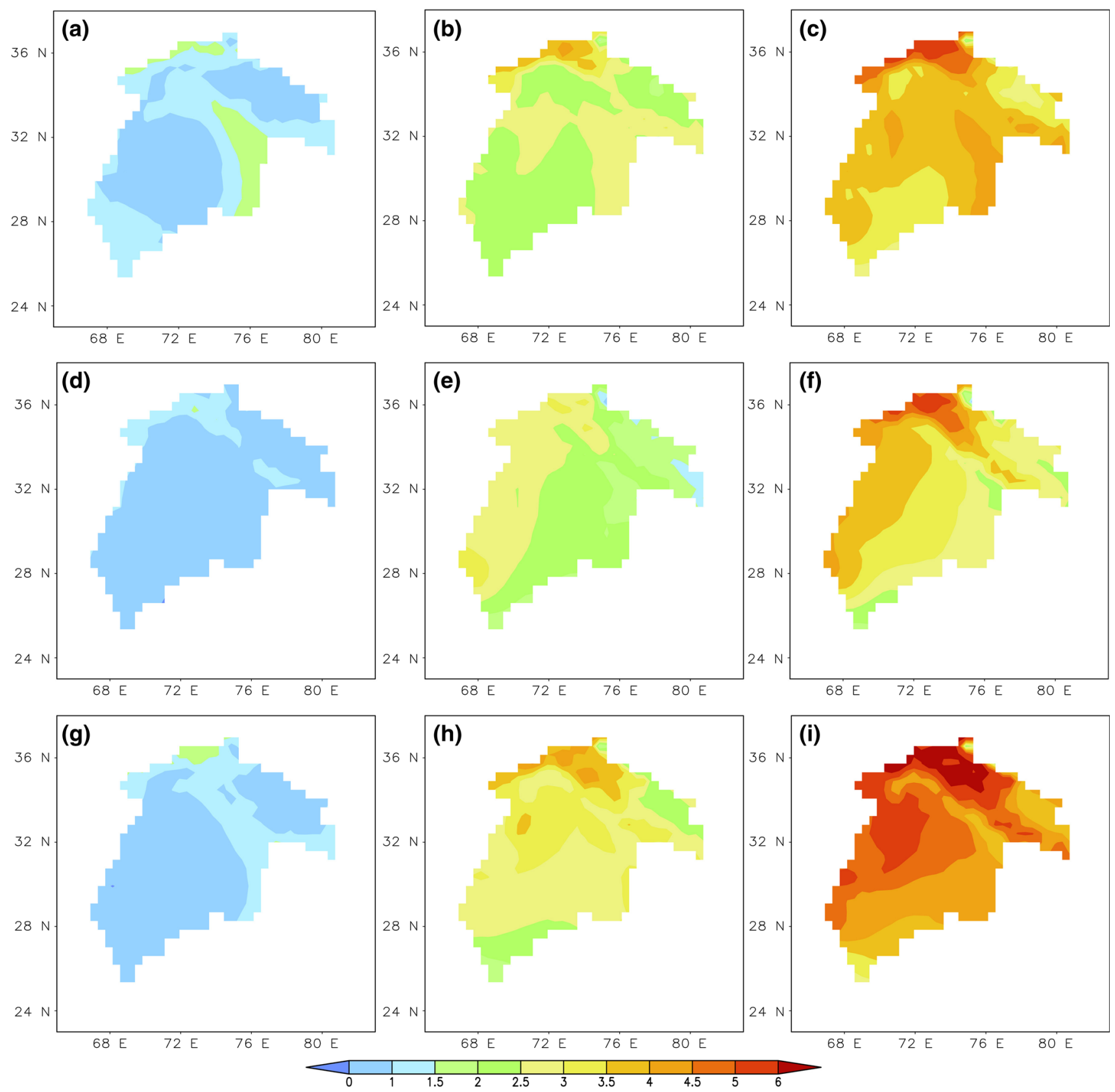

(h)

Fig. 8 Projected change in summer season maximum temperature $\left({ }^{\circ} \mathrm{C}\right.$ ) with respect to baseline 1961-1990 in the 2011-2040 (left column), 2041-2070 (middle column), and 2071-2098 (right column)

periods for the three simulations Q0 (top row), Q1 (middle row), and Q14 (bottom row)

(2071-2098) for all seasons except the months May and June. The increase is more marked in the monsoon season. The Q1 and Q14 simulations do not provide a clear indication of change; several periods show an increase in precipitation in the 2020 s followed by a decrease in the 2050s and 2080s.

The Q0 and Q14 projections suggest changes in the intra-annual pattern in precipitation in the upper Indus with a significant overall increase and that there could be an increase in precipitation from November to March. The changes are clear for all three simulations in the upper Indus, but not as clear in the lower Indus (not shown).

\subsubsection{Projected changes in annual cycles, temperature}

The baseline and projected monthly maximum and minimum temperatures for three simulations are shown 

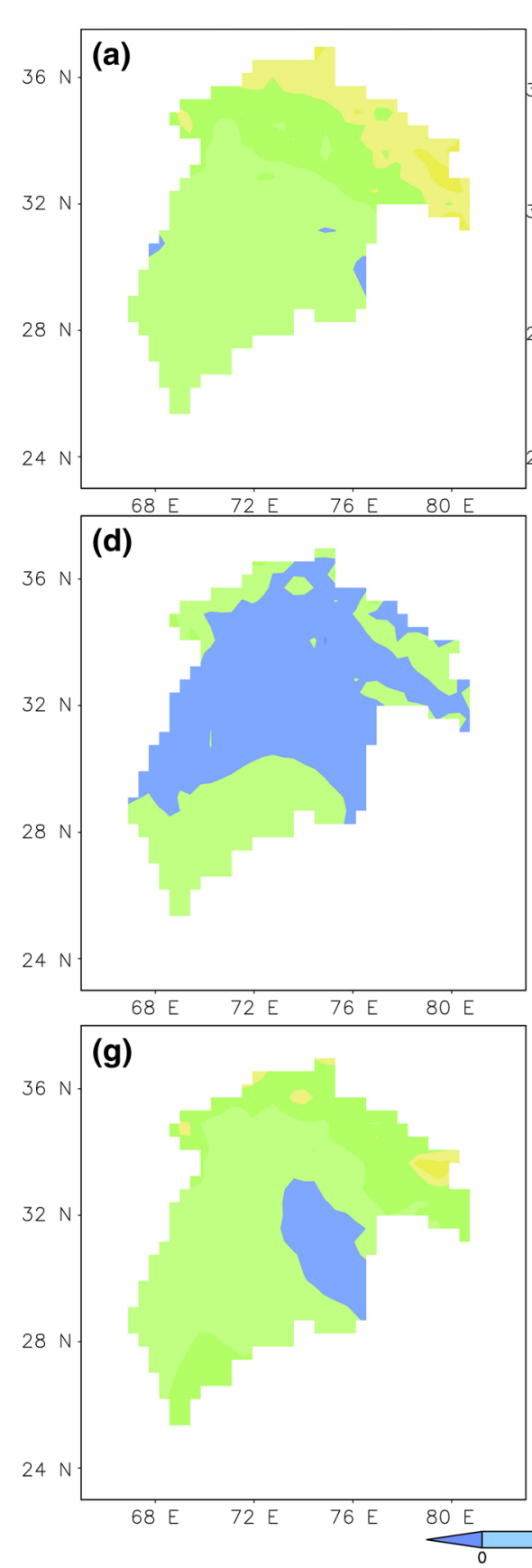

Fig. 9 Projected change in winter season minimum temperature $\left({ }^{\circ} \mathrm{C}\right)$ with respect to baseline 1961-1990 in the 2011-2040 (left column), 2041-2070 (middle column), and 2071-2098 (right column) periods

in Fig. 6 (lines). The monthly mean minimum and maximum temperatures show a consistent rise in the 2020s, 2050s, and 2080s in all three simulations over both the upper and lower parts of the Indus basin, but the overall shape of the annual cycle is unchanged. The temperature rise may be greater in the non-monsoon months.

(h)
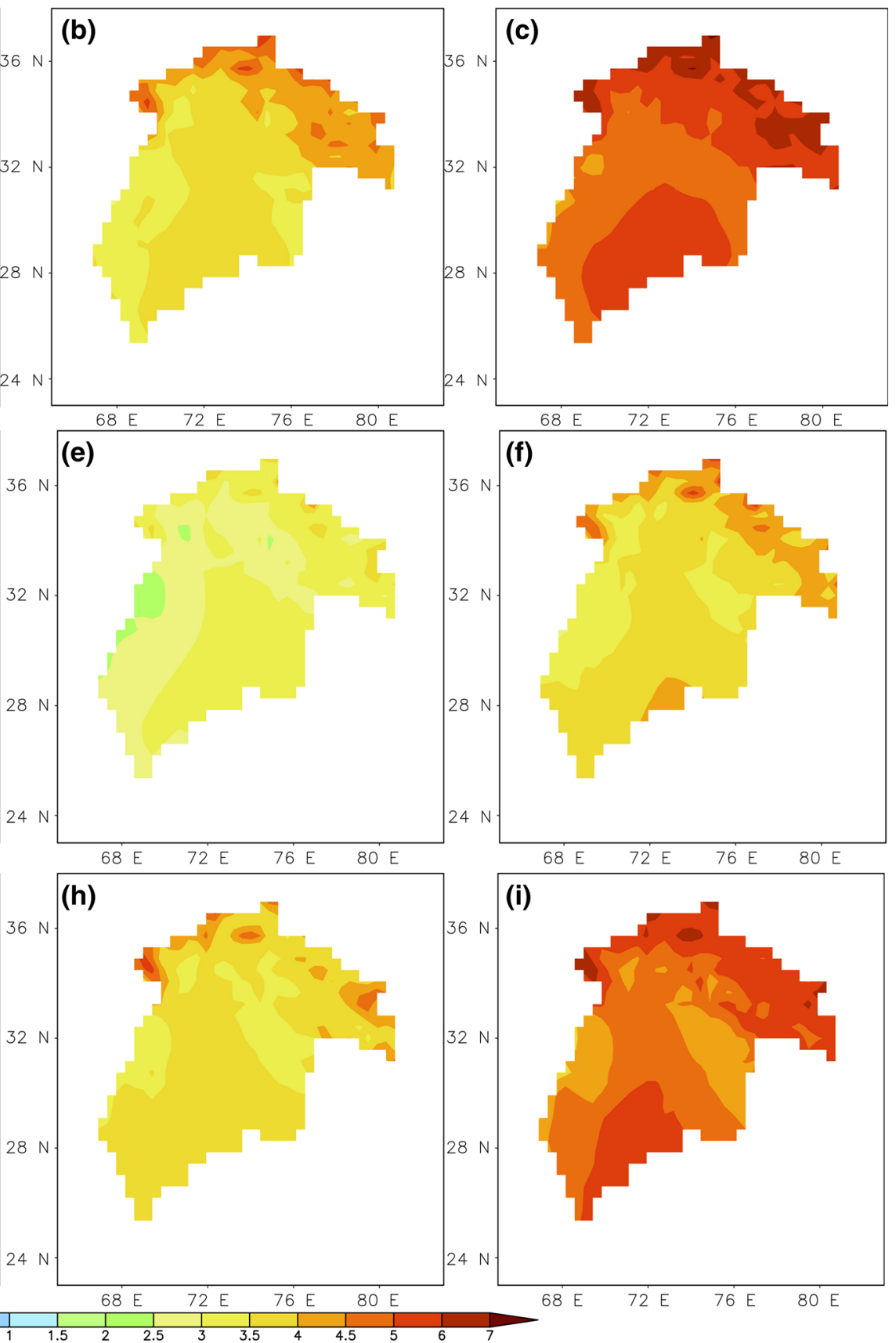

for the three simulations Q0 (top row), Q1 (middle row), and Q14 (bottom row)

\subsubsection{Projected changes in spatial distribution, precipitation}

The projected spatial distribution of seasonal rainfall changes over the whole Indus basin in the three future periods as simulated by Q0, Q1, and Q14 is given for the summer monsoon in Fig. 7. All three simulations suggest 

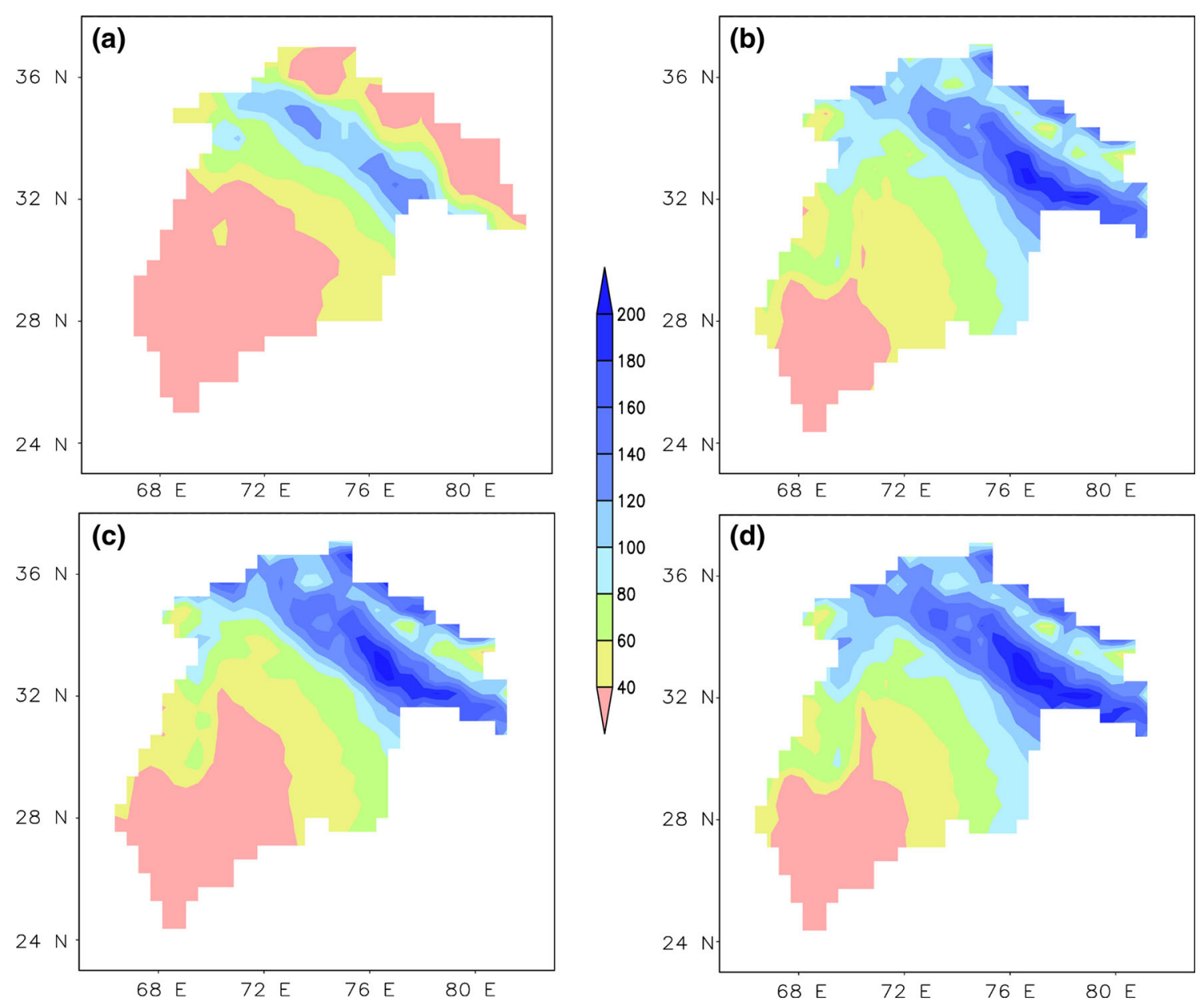

Fig. 10 Number of rainy days as simulated by PRECIS compared with observed rainy days for the baseline period 1961-1990 a APHRODITE, b Q0, c Q1, and d Q14

generally increasing monsoon precipitation in the 2020s. Q0 simulations suggest a much lower rise over the whole Indus basin in the 2050s and 2080s than in the 2020s. Q1 simulations indicate a decrease in monsoon precipitation in the southern and north-western parts of the basin in the 2050s and 2080s. Q14 simulations suggest little change in seasonal precipitation in the 2050 s, but an increase in precipitation in the north eastern part of the basin compared to the baseline in the 2080s.

All simulations suggest a decrease in precipitation during the winter season over the southern part of the basin, and an increase over the upper part of the basin, in the 2020s. In the 2050s, Q0 suggests a marked increase in rainfall over most parts of the basin whereas Q1 and Q14 suggest a marked decrease over most parts of the lower Indus.

Overall the projected regional rainfall changes are broadly consistent with the general observation "the wet gets wetter and the dry become drier" (IPCC 2007).

\subsubsection{Projected changes in spatial distribution, temperature}

The spatial distribution of mean maximum summer temperatures is shown in Fig. 8. The annual values for the maximum and minimum temperatures are given in Tables 2 and 3 respectively. All three scenarios indicate a warming trend during the summer monsoon season, with a small rise in maximum mean temperature (about $1.0-1.5^{\circ} \mathrm{C}$ ) in the $2020 \mathrm{~s}$. Q14 suggests the highest warming, with the greatest change in the northernmost part of the basin and significant warming across a large area in the west of the lower Indus.

The simulations also suggest an increasing trend in temperature during the winter season (Fig. 9). Generally the rise in minimum temperature was greater over the upper Indus basin, especially in the northern part, with only a small rise over the central part of the lower Indus basin. 

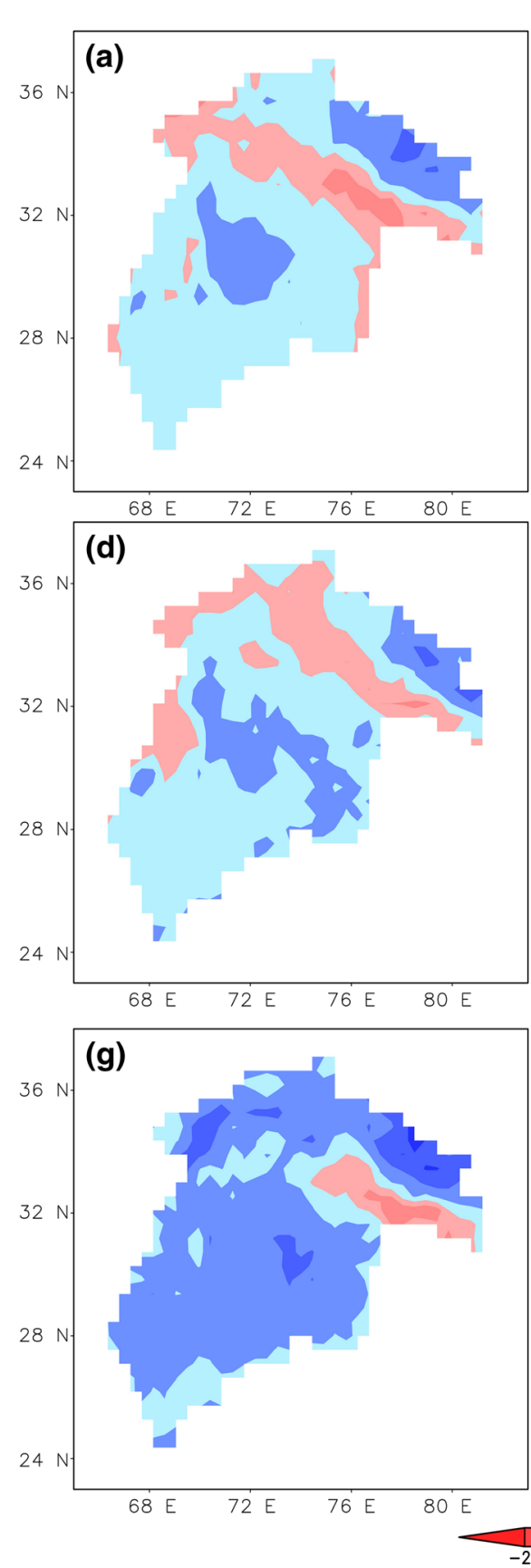

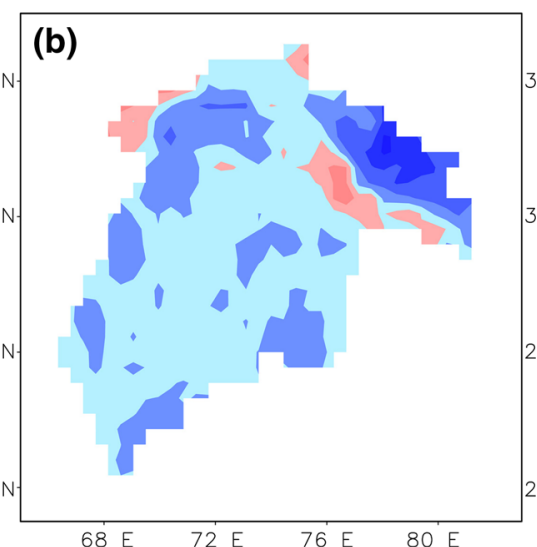

(e)

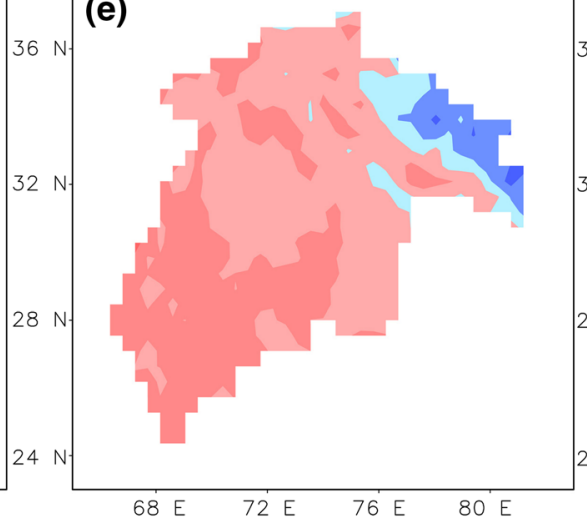

(I)

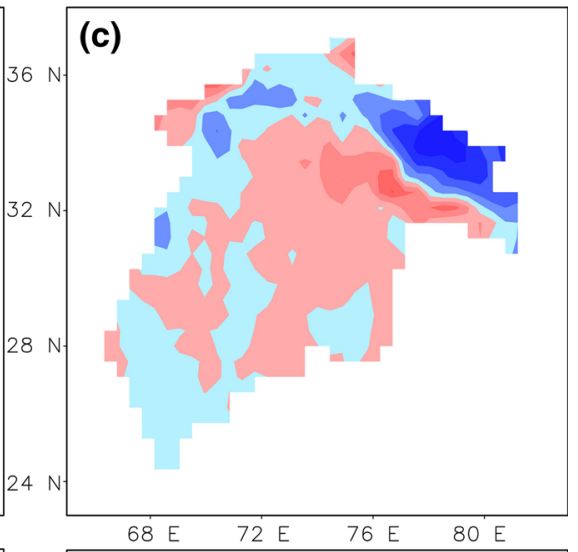

(f)

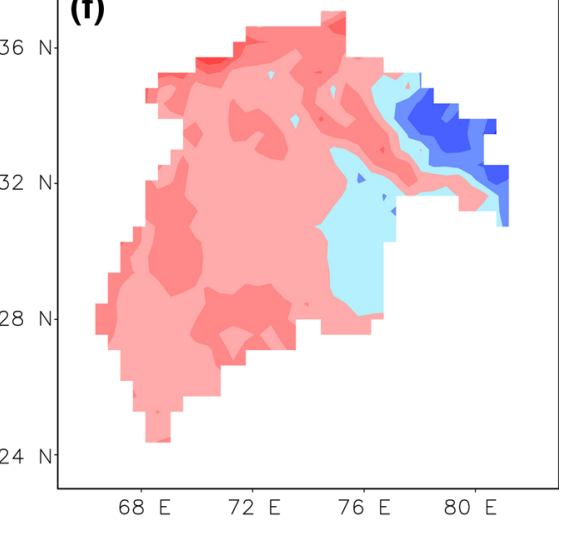

(h)

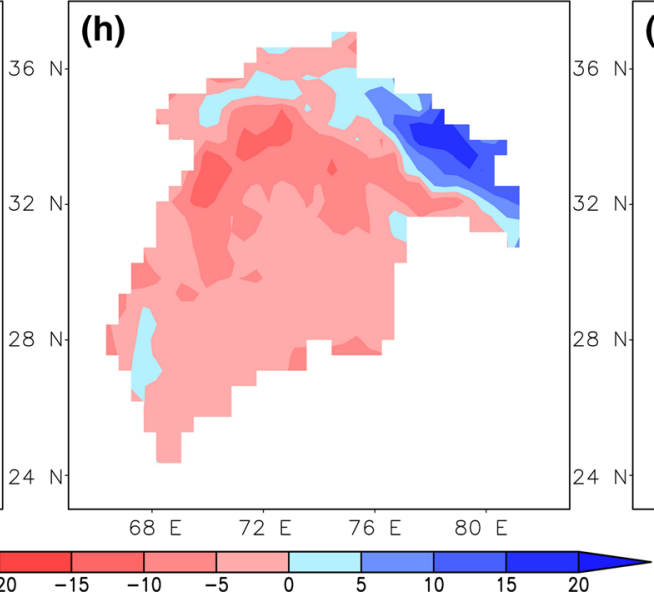

(i)

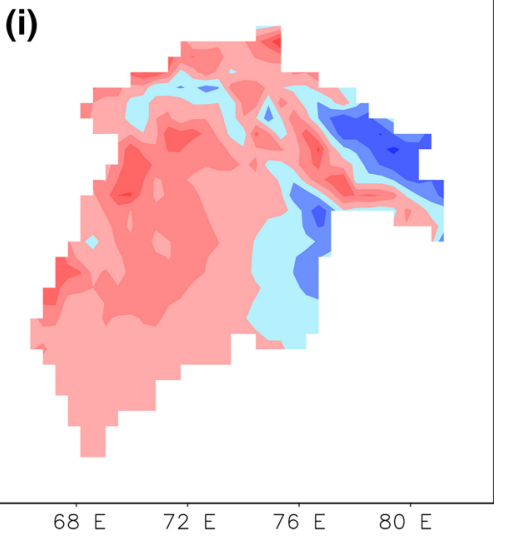

Fig. 11 Projected change in number of rainy days with respect to baseline 1961-1990 in the 2011-2040 (left column), 2041-2070 (middle column), and 2071-2098 (right column) periods for the three simulations Q0 (top row), Q1 (middle row), and Q14 (bottom row)

The rise in minimum temperature over the whole basin was up to $2{ }^{\circ} \mathrm{C}$ in the $2020 \mathrm{~s}, 2.5-4{ }^{\circ} \mathrm{C}$ in the 2050 s, and more than $4{ }^{\circ} \mathrm{C}$ in the 2080s.

The three simulations Q0, Q1, and Q14 gave average rises across the whole basin in the 2080s from the baseline of $4.3,3.9$, and $5.1{ }^{\circ} \mathrm{C}$ in the annual minimum temperature, and $4.0,3.4$, and $4.6{ }^{\circ} \mathrm{C}$ in the summer maximum temperature, respectively. In other words, the projected rise in minimum temperature is more than the rise in maximum temperature. This indicates that the Indus basin may experience warmer winters in the future.

\subsection{Analysis of extreme events}

\subsubsection{Precipitation}

The Indus basin is particularly prone to floods and flash floods. Prediction of changes in extreme precipitation 

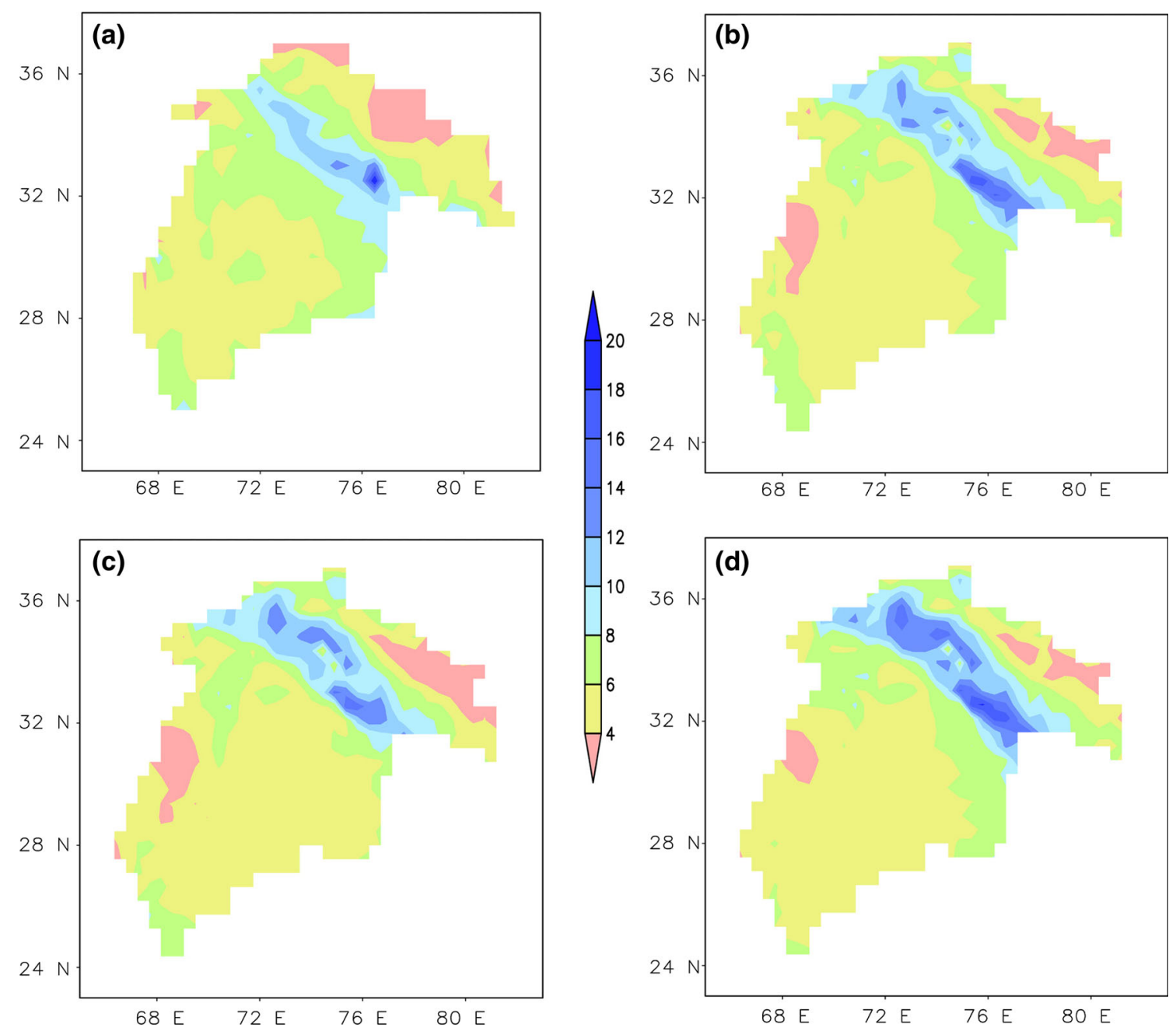

Fig. 12 Intensity of rainfall (mm/day) on rainy days over the Indus basin for the baseline period 1961-1990 according to observation and PRECIS simulation: a APHRODITE, b Q0, c Q1, and d Q14

events can provide insights into likely changes in the magnitude and frequency of floods and flash floods, which in turn can help in planning appropriate mitigation measures. In order to study the impact of extreme events, we analysed the frequency of rainy days and the rainfall intensity. Figure 10 shows the number of rainy days for the baseline period 1961-1990 as calculated from gridded daily rainfall data and estimated by Q0, Q1, and Q14 simulations. The spatial pattern of the model results is very similar to the observed pattern but the model results show a higher number of rainy days especially in the north eastern part of the basin.

The projected changes in rainy days are shown in Fig. 11. All three simulations show an increase in the number of rainy days in the 2020s over most parts of the basin, with a decrease in the border area between the upper and lower Indus basins, the area with the highest amount of rainfall. All three simulations show an increase in rainy days over the northeastern part of the upper Indus basin in all three time periods. The Q0 simulation showed an increase in the number of rainy days in the 2050s, followed by a decrease over the central part of the basin in the 2080s. The Q1 and Q14 simulations indicate a decrease in rainy days over most part of the basin in the 2050s and 2080s with a slight increase over the eastern portion of the central Indus area.

Figure 12 shows the simulated rainfall intensity $(\mathrm{mm} /$ day) for the baseline period 1961-1990 as calculated from gridded daily rainfall data and estimated by Q0, Q1, and Q14 simulations. The spatial pattern of the model results is very similar to the observed pattern. The projected changes in rainfall intensity are shown in Fig. 13. Q0 simulation show slight decrease in the intensity towards northwest part of the basin in 2020s and progressively increases towards 2080s. All three simulations indicate increase of rainfall intensity over the northeast part of the border area between lower Indus and upper Indus towards 2080s. 

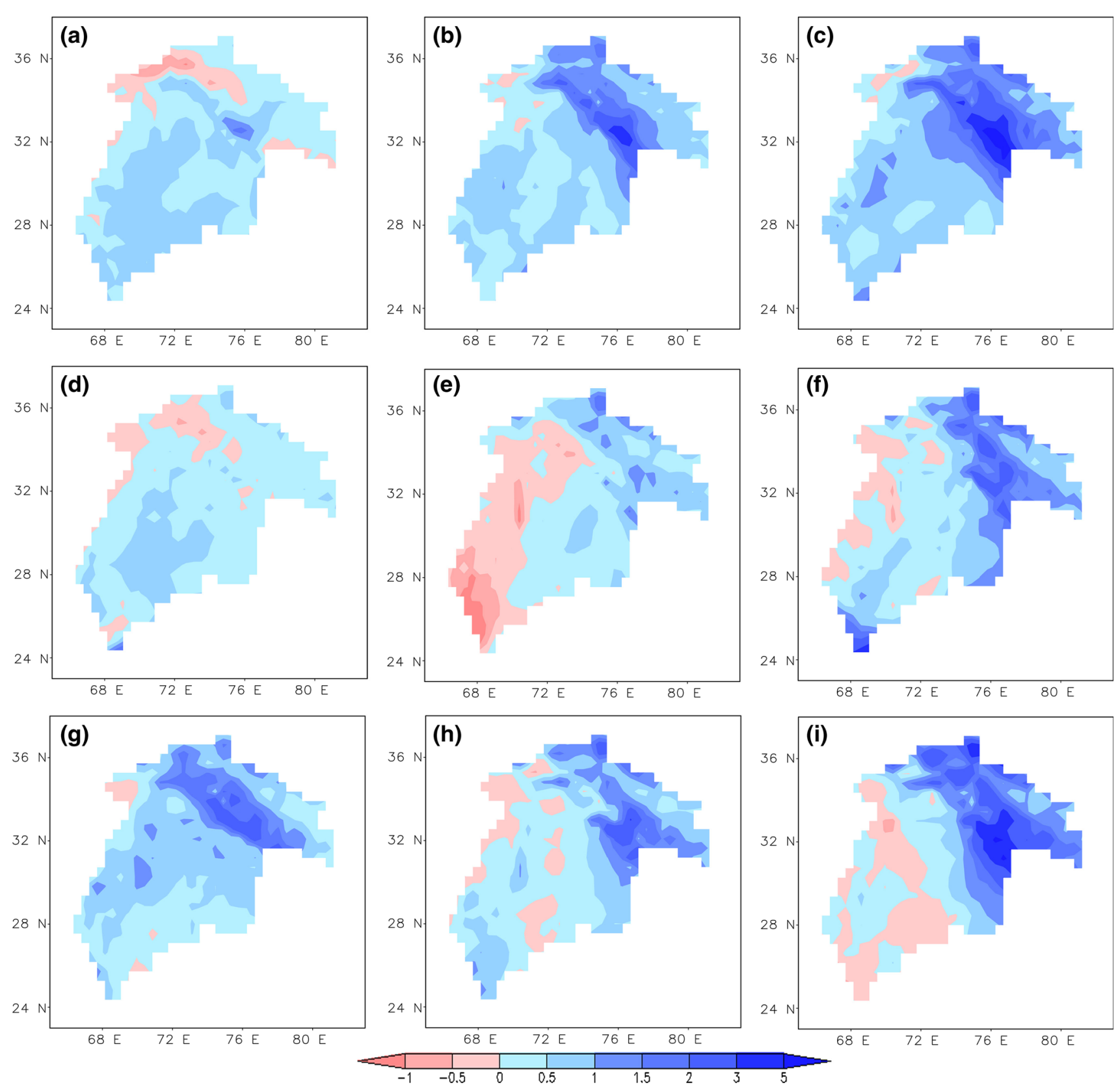

Fig. 13 Projected change in intensity of rainfall $(\mathrm{mm} /$ day) on rainy day with respect to baseline period of 1961-1990 in the 2011-2040 (left column), 2041-2070 (middle column), and 2071-2098 (right

column) periods for the three simulations Q0 (top row), Q1 (middle row), and Q14 (bottom row)

\subsubsection{Temperature}

Temperature extremes were investigated by analysing highest maximum (summer daytime) and lowest minimum (winter night time) temperatures. The $1{ }^{\circ} \mathrm{C}$ bias corrected maximum and minimum temperature datasets generated by the Princeton University Hydroclimatology group (Sheffield et al. 2006) available for 1948-2007 were used as observation estimates for extreme temperature events. Figure 14 shows the lowest minimum temperatures as estimated by the Princeton University dataset, Q0, Q1, and Q14 simulations for the baseline period 1961-1990. The spatial patterns of the PRECIS simulations are similar to those of the observed values, but model values are higher for extreme maximum values and lower for extreme minimum values.

All three simulations show an increase in highest maximum temperatures throughout the basin in the 2050s and 2080s. In the 2020s, the Q1 and Q14 simulations show a decrease in extreme temperature events in small pocket 

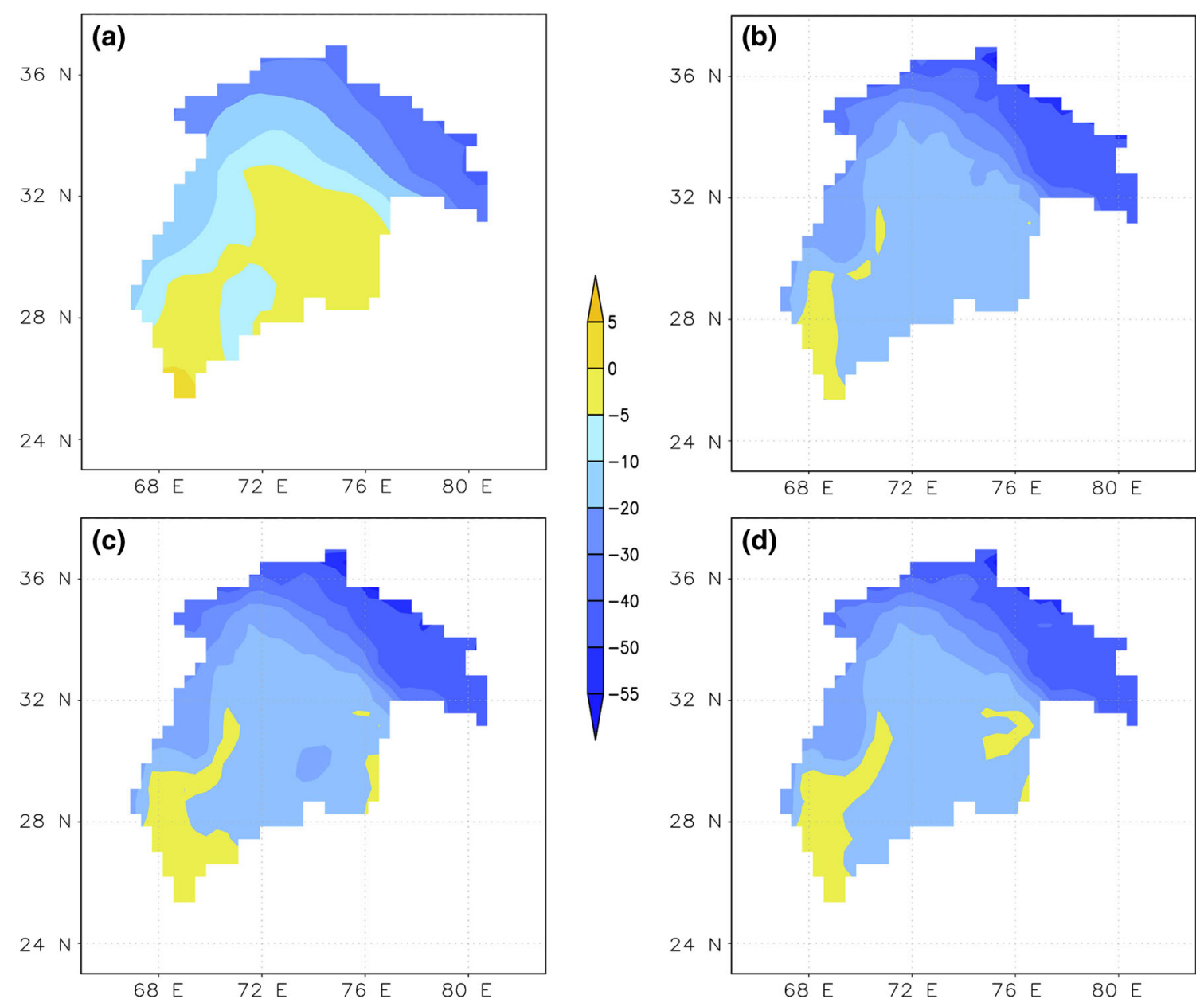

Fig. 14 Lowest minimum temperatures $\left({ }^{\circ} \mathrm{C}\right)$ over the Indus basin according to observation and PRECIS simulations for the baseline period 1961-1990 a Princeton University Hydroclimatology Group generated dataset, b Q0, c Q1, and d Q14

areas. The Q0 and Q14 simulations show a rise in maximum temperatures of $4-8{ }^{\circ} \mathrm{C}$, and $\mathrm{Q} 1$ of $4-6{ }^{\circ} \mathrm{C}$, over most parts of the basin in the 2080s.

The projected increases in lowest minimum temperature are greater than the projected increases in highest maximum temperature, but the projections do not show any systematic pattern (Fig. 15). All simulations show a rise of more than $4{ }^{\circ} \mathrm{C}$ throughout the basin in the 2080s, with an increase of more than $8{ }^{\circ} \mathrm{C}$ over the border area between the upper and lower Indus basins. Significant warming, particularly in the upper basin could mean enhanced melting of the snow cover and glaciers leading to changes in the hydrological regime of the basin.

\section{Conclusion}

The future changes in rainfall and temperature driven by three LBC using A1B scenario as simulated by regional climate model PRECIS is presented. The major conclusions are as follow:

- The regional climate model (PRECIS) showed good skill in capturing the surface climate scenario over the Indus basin both for rainfall and temperatures. There was an overestimation of rainfall for both summer and winter seasons. There was a warm bias in the maximum temperatures in and monsoon season, a slight cold bias in minimum temperatures during the winter and postmonsoon seasons, and a cold bias in winter minimum temperature towards higher altitude areas.

- The projected change in summer monsoon precipitation was non-uniform over the basin. The spatial pattern also differed considerably in the different simulations suggesting uncertainties in the future change. In the winter season, the results indicated an increase in precipitation over the upper Indus basin and decrease over the lower Indus basin. 

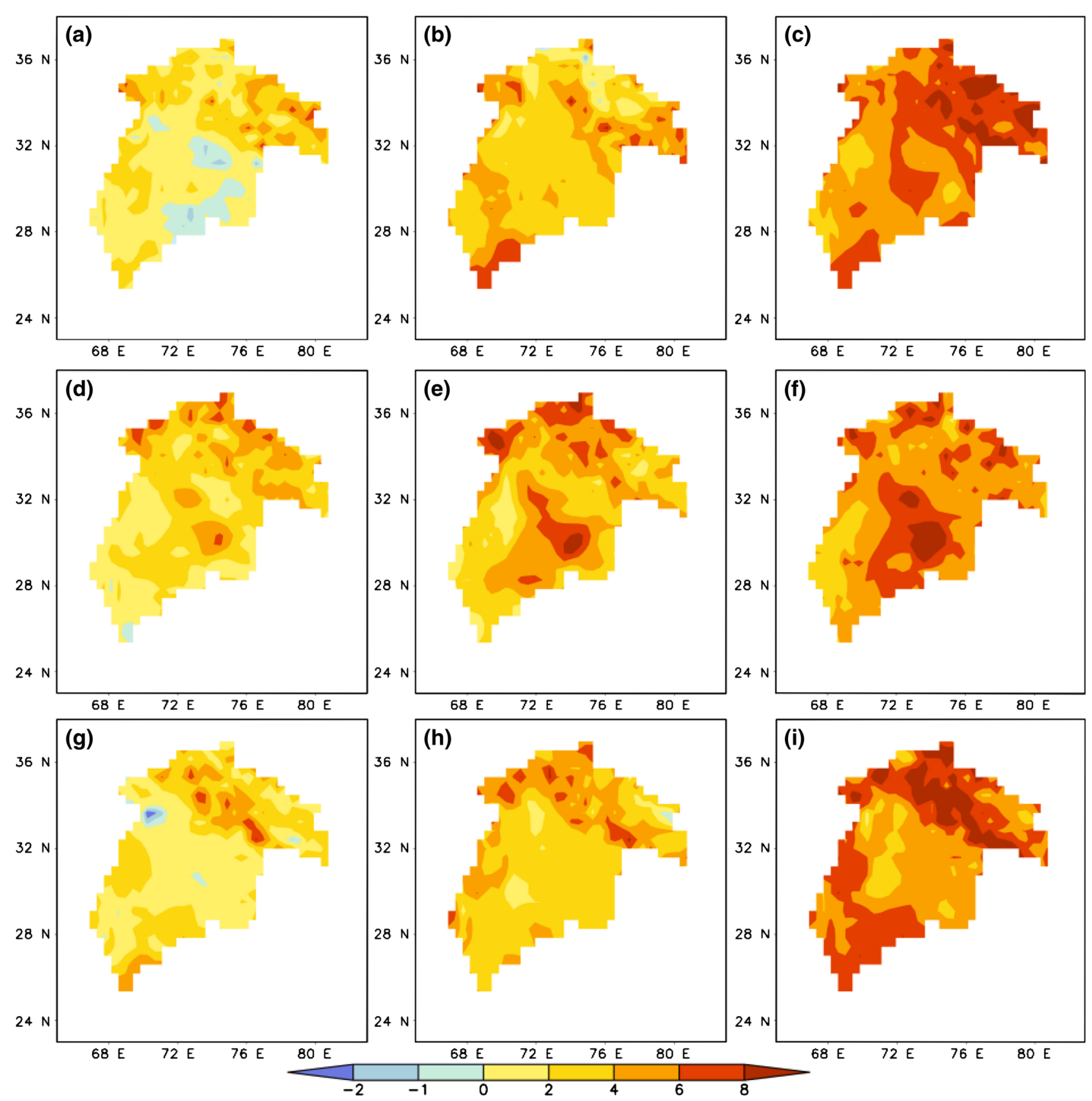

Fig. 15 Projected change in the lowest daily minimum temperature $\left({ }^{\circ} \mathrm{C}\right)$ with respect to baseline 1961-1990 in the 2011-2040 (left column), 2041-2070 (middle column), and 2071-2098 (right column) periods for the three simulations Q0 (top row), Q1 (middle row), and Q14 (bottom row)
- The Indus basin overall was projected to warm significantly and progressively over all three time periods, with a slightly greater increase in minimum temperatures than in maximum temperatures for all time slices. Warming was projected to be greater in winter than in the other seasons and greater in the upper Indus basin than the lower Indus basin, with a large area to the west of the basin projected to warm significantly. There was greater agreement between simulations for temperature than for precipitation. The projected changes in temperature could have a negative impact on snow cover and glacial mass in the upper Indus basin and on the water resources of the whole basin.

- All three simulations suggested an increase in the number of rainy days over the northern part of the basin 
and decrease over the southern part. The model projected a decrease in rainy days with an increase in rainfall intensity over the border area between the upper and lower basins, where the rainfall amount is highest, in the 2080s. The border area between the upper and lower Indus is prone to flash floods and a source of large floods, thus the projected changes in extreme events are likely to exacerbate the flood and flash flood hazard in this part of the basin.

- Both the highest maximum and lowest minimum temperatures were projected to increase, with a greater increase in the lowest minimum temperature.

While the scenarios presented here are indicative of an expected range of rainfall and temperature changes, it is important to note that the quantitative estimates and projections contain significant uncertainties. The study was limited by the small number of simulations based on a single regional climate model. Nevertheless the outputs provide useful inputs for various types of impact assessment over the basin for future years. More detailed information can be obtained from the authors.

Acknowledgments This study was a part of Himalayan Climate Change Adaptation Programme (HICAP). HICAP is implemented jointly by ICIMOD, CICERO and UNEP/GRID-Arendal and is supported by the Ministry of Foreign Affairs Norway and Swedish International Development Agency (Sida). This study was partially supported by core funds of ICIMOD contributed by the governments of Afghanistan, Australia, Austria, Bangladesh, Bhutan, China, India, Myanmar, Nepal, Norway, Pakistan, Switzerland, and the United Kingdom. The authors would like to express sincere gratitude to the Indian Institute of Tropical Meteorology (IITM) for providing the PRECIS simulated data for the present analysis.

Open Access This article is distributed under the terms of the Creative Commons Attribution License which permits any use, distribution, and reproduction in any medium, provided the original author(s) and the source are credited.

\section{References}

Adam J, Lettenmaier DP (2003) Adjustment of global gridded precipitation for systematic bias. J Geophys Res 108:1-14. doi:10.1029/2002JD002499

Bhaskaran B, Jones RJ, Murphy JM, Noguer M (1996) Simulations of the Indian summer monsoon using a nested regional climate model: domain size experiments. Clim Dyn 12:573-587

Bhaskaran B, Murphy JM, Jones RG (1998) Intraseasonal oscillation in the Indian summer monsoon simulated by global and nested regional climate models. Mon Weather Rev 126:3124-3134

Bhaskaran B, Ramachandran A, Jones R, Okia WM (2012) Regional climate model applications on sub-regional scales over the Indian monsoon region: the role of domain size on downscaling uncertainty. J Geophys Res 117:D10113. doi:10.1029/2012 JD017956

Briscoe J (2010) Troubled waters: Can a bridge be built over the Indus? Econ Polit Wkly 45:28-32
Collins M, Booth BBB, Harris GR, Murphy JM, Sexton DMH, Webb MJ (2006) Towards quantifying uncertainty in transient climate change. Clim Dyn 27:127

Dimri A (2012) Wintertime land surface characteristics in climatic simulations over the western Himalayas. J Earth Syst Sci 121:329-344

EP UN (2008) UNEP sourcebook integrating adaptation to climate change into UNEP programming. United Nations Environment Programme, Nairobi

Eriksson M, Xu J, Shrestha AB, Vaidya RA, Nepal S, Sandström K (2009) The changing Himalayas: impact of climate change on water resources and livelihoods in the greater Himalayas. ICIMOD, Kathmandu

Giorgi F, Mearns L (1999) Introduction to special section: regional climate modeling revisited. J Geophys Res 104(D6):6335-6352. doi:10.1029/98JD02072

Immerzeel WW, Droogers P, Jong SMD, Bierkens MFP (2009) Large-scale monitoring of snow cover and runoff simulation in Himalayan river basins using remote sensing. Remote Sens Environ 113(1):40-49

Immerzeel W, Beek LV, Bierkens M (2010) Climate change will affect the Asian water towers. Science 328:1382-1385

IPCC (2007) Climate change 2007: the Physical Science Basis Contribution of Working Group I to the Fourth Assessment Report of the IPCC (ISBN 9780521 88009-1 Hardback; 978 0521 70596-7 Paperback)

Jones RG, Noguer M, Hassell DC, Hudson D, Wilson SS, Jenkins GJ, Mitchell JFB (2004) Generating high resolution climate change scenarios using PRECIS. Met Office Hadley Centre, Exeter

Kamala K (2008) Regional climate change projections for India : development of high-resolution climate scenarios for impact assessment for the 21 st century. Ph. D. thesis, University of Pune

Kripalani RH, Oh JH, Kulkarni A, Sabade SS, Chaudhari HS (2007) South Asian summer monsoon precipitation variability: coupled climate model simulations and projections under IPCC AR4. Theor Appl Climatol 90:133-159. doi:10.1007/s00704-0060282-0

Kumar KK, Patwardhan SK, Kulkarni A, Kamala K, Rao KK, Jones R (2011) Simulated projections for summer monsoon climate over India by a high-resolution regional climate model (PRECIS). Curr Sci 101:312-326

Murphy JM, Sexton DMH, Barnett DN, Jones GS, Webb MJ, Collins MC, Stainforth DA (2004) Quantification of modelling uncertainties in a large ensemble of climate change simulations. Nature 430:768-772

New M, Lister D, Hulme M, Makin I (2002) A high-resolution data set of surface climate over global land areas. Clim Res 21: $1-25$

Noguer M, Jones R, Hessel D, Hudson D, Wilson S, Jenkins J, Mitchell J (2002) Workbook on generating high resolution climate change scenarios using PRECIS. Hadley Centre for Climate Prediction and Research, Met Office, Bracknell

Patwardhan SK (2013) The study of impact of climate change on the characteristics of indian summer monsoon using regional climate model, $\mathrm{Ph}$. D. Thesis, University of Pune

Rees HG, Collins DN (2006) Regional differences in response of flow in glacier-fed Himalayan rivers to climatic warming. Hydrol Process 20:2157-2169

Rupa Kumar K, Sahai AK, Kumar KK, Patwardhan SK, Mishra PK, Revadkar JV, Kamala K, Pant GB (2006) High-resolution climate change scenario for India for the 21 st century. Curr Sci 90:334-345

Sabade SS, Kulkarni A, Kripalani RH (2011) Projected changes in South Asian summer monsoon by multi-model global warming experiments. Ther Appl Climatol 103:543-565 
Sheffield J, Goteti G, Wood EF (2006) Development of a 50-year high-resolution global dataset of meteorological forcings for land surface modeling. J Clim 19(13):3088-3111

Singh S, Khadka BI, Karky B, Sharma E (2011) Climate change in the Hindu Kush-Himalayas: the state of current knowledge. ICIMOD, Kathmandu

Stainforth DA, Aina T, Christensen C, Collins M, Faull N, Frame DJ, Kettleborough JA, Knight S, Martin A, Murphy JM, Piani C, Sexton D, Smith LA, Spicer RA, Thorpe AJ, Allen MR (2005) Uncertainty in predictions of the climate response to rising levels of greenhouse gases. Nature 433:403-406

Suh M-S, Lee D-K (2004) Impact of landuse/cover changes on surface climate over East Asia for extreme climate cases using RegCM2. J Geophys Res 109:1-14

Syed FS, Iqbal W, Syed AB, Rasul G (2013) Uncertainties in the regional climate models simulations of South-Asian summer monsoon and climate change, Clim Dyn. doi:10.1007/s00382013-1963-x

Terrestrial Hydrology Research Group (2013) Global meteorological forcing dataset for land surface modelling. http://hydrology. princeton.edu/data.pgf.php. Accessed 17 Dec 2013

Turner AG, Annamalai H (2012) Climate change and the South Asian summer monsoon. Nat Clim Change 2:587-595

Vannitsem S, Chome F (2005) One-way nested regional climate simulations and domain size. J Clim 18:229-233

Xue Y, Fennessy MJ, Sellers PJ (1996) Impact of vegetation properties on US summer weather prediction. J Geophys Res 101:7419-7430

Yatagai A, Kamiguchi K, Arakawa O, Hamada A, Yasutomi N, Kitoh A (2012) APHRODITE: constructing a long-term daily gridded precipitation dataset for Asia based on a dense network of rain gauges. Bull Am Meteorol Soc 93:1401-1415 